Fish \& Shellfish Immunology

September 2015, Volume 46, Issue 1, Pages 50-64

http://dx.doi.org/10.1016/i.fsi.2015.02.040

http://archimer.ifremer.fr/doc/00254/36552/

(c) 2015 Elsevier Ltd. All rights reserved.

\title{
The new insights into the oyster antimicrobial defense: Cellular, molecular and genetic view
}

\author{
Bachère Evelyne ${ }^{2,{ }^{*}}$, Rosa Rafael Diego ${ }^{1,3}$, Schmitt Paulina ${ }^{1,4}$, Poirier Aurore ${ }^{1,2}$, Merou Nicolas ${ }^{1}$, \\ Charrière Guillaume M. ${ }^{1,2}$, Destoumieux Garzon Delphine ${ }^{1,2}$
}

${ }^{1}$ UMR 5244, IHPE Interaction Host Pathogen Environment, UPVD, CNRS, Université de Montpellier, CC 80, F-34095 Montpellier, France

${ }^{2}$ Ifremer, Montpellier, France

${ }^{3}$ Laboratory of Immunology Applied to Aquaculture, Department of Cell Biology, Embryology and Genetics, Federal University of Santa Catarina, 88040-900 Florianópolis, SC, Brazil

${ }^{4}$ Laboratorio de Genética e Inmunología Molecular, Instituto de Biología, Pontificia Universidad, Católica de Valparaíso, Avenida Universidad 330, 2373223 Valparaíso, Chile

${ }^{*}$ Corresponding author : Evelyne Bachère, tel.: +33467144710 ;

email address : ebachere@ifremer.fr

\begin{abstract}
:
Oysters are sessile filter feeders that live in close association with abundant and diverse communities of microorganisms that form the oyster microbiota. In such an association, cellular and molecular mechanisms have evolved to maintain oyster homeostasis upon stressful conditions including infection and changing environments. We give here cellular and molecular insights into the Crassostrea gigas antimicrobial defense system with focus on antimicrobial peptides and proteins (AMPs). This review highlights the central role of the hemocytes in the modulation and control of oyster antimicrobial response. As vehicles for AMPs and other antimicrobial effectors, including reactive oxygen species (ROS), and together with epithelia, hemocytes provide the oyster with local defense reactions instead of systemic humoral ones. These reactions are largely based on phagocytosis but also, as recently described, on the extracellular release of antimicrobial histones (ETosis) which is triggered by ROS. Thus, ROS can signal danger and activate cellular responses in the oyster. From the current literature, AMP production/release could serve similar functions. We provide also new lights on the oyster genetic background that underlies a great diversity of AMP sequences but also an extraordinary individual polymorphism of AMP gene expression. We discuss here how this polymorphism could generate new immune functions, new pathogen resistances or support individual adaptation to environmental stresses.
\end{abstract}

Keywords : mollusk, immunity, antimicrobial peptide, hemocyte, defensin 


\section{Introduction}

Oysters are bivalve mollusks belonging to the Ostreidae family (Mollusca, Bivalvia, Lophotrochozoa). They are sessile filter-feeders living in shallow water from intertidal zones of bays, lagoons and estuaries. In these habitats, oysters are confronted and adapted to great changes in biotic and abiotic environmental conditions. Abiotic factors include temperatures and salinity fluctuations but also exposure to xenobiotics and water acidification due to human activities. Biotic factors include abundant and diverse populations of microbes. As filter feeders, oysters are in permanent contact and exchanges with microorganisms. Thus, they harbor on their surfaces and inside their body cavities and hemolymph a dense microbiota which has been shown to be greatly dominated by Vibrio species [1,2]. Indeed, a large attention has been paid over the past years, to populations of vibrios as they are among the most abundant cultivable bacteria isolated from oyster tissues [3]. In healthy oyster, bacteria load, including vibrio, has been shown to vary over time according to individuals and to temperature, with hemolymph average concentrations of 5,7 colonies forming unit (CFU) per $\mu \mathrm{L}[2,4]$. Hence, oyster must be seen as an organism associated to a microbiota (including mutualistics, opportunists and pathogens), that has adapted effective cellular and molecular mechanisms for maintaining homeostasis and health status in stressful and changing environments. The multifactorial diseases affecting Crassostrea gigas oysters worldwide [5] are the outcome of an equilibrium collapse in the interplay between the biotic and abiotic environmental factors such as microorganisms and temperature [6], on the one hand, and the oyster physiology and immune responses on the other hand [7].

By focusing on $C$. gigas, we propose here to give cellular and molecular insights into the oyster antimicrobial defense system considering the genetic background of individuals.

\section{1- Effectors of the antimicrobial defense}

Oyster immunity involves not only hemolymph-mediated reactions, but also immune effectors produced by epithelial cells from various organs, including gills, mantle, digestive gland and intestine, which participate in the antimicrobial defense mechanisms.

\section{1-1 Plasma proteins}

As oysters have a semi-open circulatory system, hemolymph is typically an important interface between the immune system and the microorganisms that enter the oyster body. The oyster hemolymph is devoid of clotting reaction by means of plasma gelation but the hemocytes display remarkable spontaneous reaction of aggregation resulting in cellular clot [8]. Aggregation is reversible, the hemocytes can further disperse and re-enter the circulating system. In vitro hemocyte 
aggregation has been shown to be inhibited by recombinant tetraspanin [9] which participates to cell-adhesion molecular complexes of mammalian white cells. To date, no respiratory protein has been characterized in Ostreoidae bivalves but strikingly, the oyster plasma is characterized by the over representation of proteins that present homologies with extracellular metalloenzyme Superoxide Dismutases (EcSODs). Named dominin [10], cavortin [11] or EcSOD [12,13], these proteins could belong to a complex family of multifunctional molecules [5]. For instance, one member of this family, $C g$-EcSOD, has LPS-binding properties and acts as an opsonin for pathogenic vibrios (see below) $[13,14]$. To date, there is no compelling evidence that all SODrelated proteins retained SOD activities [10,11]. Thus, these circulating proteins may play major roles, even now under-explored, in the interplay with the oyster hemolymph microbiota but also in the antimicrobial defense reactions, by mediating microbe recognition and promoting phagocytosis.

\section{1-2 Oyster hemocytes}

The hemocytes (blood cells) are immunocompetent cells but they are also involved in many physiological processes such as wound and shell repair, nutrient transport and digestion, gonad resorption. As the oyster circulatory system is semi-open, hemocytes are not confined to the vessels and they invade or reside in many other tissues [15]. Thus, infiltrating hemocytes are present in all cavities, tissues and epithelia of oyster body where they can also fulfil defense functions. The term hemocytes refers to a diversity of circulating cells that is best highlighted by the lack of unified classification, although they have been extensively studied since early 1970's. Indeed, the lack of molecular and functional genetic tools has precluded any in-depth characterization of cell lineage ontogeny and discrimination of functionally distinct cell types.

Hemocyte lineage. Although a clear definition of distinct cell types is still missing, a consensus about three main cell populations, i.e. blast-like cells, hyalinocytes and granulocytes, appears in the literature as they can be distinguished either by microscopy or flow cytometry analyses [15,16]. Among hyalinocytes, also named agranular cells, a subset of professional phagocytes, which are sometimes described as macrophage-like cells, harbor a potent phagocytosis activity; they account for 30 to $40 \%$ of the total populations of hemocytes [14]. Attempts to define cell lineages and functional subsets have been reported using classical May-Grünwald Giemsa (MGG) staining, peroxidase or phosphatase staining, electron microscopy, or flow cytometry analyses [16-19]. From works in the different oyster species, some authors reported basophile and eosinophile granulocytes similar to their mammalian counterparts [16]. Other authors have drawn hypothesis of a cell maturation process in one single lineage from blast-like cells, hyalinocytes to 
granulocytes [20]. Hence the different hypotheses range from one unique lineage to numerous functionally distinct cell types from different lineages [16,20]. One caveat for most of these different reports is that most of the tools that have been used so far for hemocyte characterization were developed to analyze mammals blood cells (like the MGG staining for example) and thus have to be interpreted with caution in other species. Another caveat is that depending on the maturation stage or the functional activities of one cell type, the cell morphologies and physic-chemical characteristics may change, as for example the internal complexity of professional phagocytes that increases upon phagocytosis when analyzed by flow cytometry. Altogether, the actual number of cell lineages and functionally specialized subsets of hemocytes remain to be carefully examined and accurately determined.

Hematopoiesis. As for the distinction of the different cell types, the ontogeny of oyster hemocytes remains to be fully characterized. Different hypotheses about their hematopoietic origin have been elaborated over the past decades. Cheng (1981) proposed that hemocytes could originate from the differentiation of connective tissue cells [17]. Tirapé and colleagues (2007) described that the expression of $\mathrm{Cg}$-tal (Tal1/SCL) [21], a family of transcription factors involved during embryonic hematopoiesis in vertebrates [22] was only detected in cells emerging from blood vessel endothelium, which is reminiscent of the hematopoietic cell emergence from the hemogenic endothelium in vertebrate embryos [23,24]. More recently, a study from Jemaà and colleagues (2014) using BrdU to localize mitotic cells within the oyster tissues suggested that some hemocyte progenitors emerge from particular structures at the basement of the gill epithelium [25], which is reminiscent of assumptions made earlier by Cuénot in 1891 [26]. Altogether, this sum of potentially contradictory pieces of work highlights the lack of knowledge about hematopoiesis in oysters and more largely in bivalves. Although the recent progress in molecular biology has dramatically advanced our knowledge on the immune-function of hemocytes, little is known about oyster hemocyte life cycle and cell lineage origin. This discrepancy is probably due to the lack of dedicated molecular tools for cell lineage analysis and/or the lack of long-term cell culture systems for studying cell differentiation and maturation. Such tools gave access to a comprehensive knowledge of hematopoiesis in other animals from drosophila to human. The recent release of the full $C$. gigas genome should help to develop the required tools.

\section{1-3 Antimicrobial peptides/proteins (AMPs)}

Several gene-encoded antimicrobial peptides and proteins (AMPs) sharing common molecular features with AMP families described in other kingdoms of life have been characterized in oysters 
(Table 1). These host defense effectors are usually small cationic (less than $10 \mathrm{kDa}$ ), amphipathic peptides showing a broad diversity of amino acid sequence and structural conformations [27,28]. However, some large cationic proteins with antimicrobial properties have also been described (Table 1). Based on common structural features or conserved sequence motifs characteristics for AMP families, oyster antimicrobials have been classified as defensins, big defensins, proline-rich AMPs and bactericidal/permeability-increasing (BPI) proteins. More recently, two molecules with antimicrobial activities, the Macrophage expressed gene1-like protein and the Molluscidin peptide have also been characterized in oysters. An overview of the characteristics of the main oyster antimicrobials is proposed in Table 1 and their amino acid sequences are presented in Table 2.

\section{1-3-1 Defensins (Cg-Defs)}

Defensins are by far the best described AMPs from oysters. Since their first isolation from mussels [29,30], defensins have been identified in diverse species of mollusks. The first defensin characterized in oysters has been purified from acidified gill extracts of the American oyster $C$. virginica [31]. Then, in C. gigas, three representative members of defensins have been identified by genomic approach as expressed in the mantle epithelia, $C g$-Defm [32], and in the hemocytes, namely $C g$-Defh1 and $C g$-Defh2 [33]. A broad diversity of defensin sequences was found in $C$. gigas (see "AMP genomic diversity and evolution" section below).

- Gene organization. Each $C g$-Def is encoded by a separate gene with different genomic organization. The mantle defensin genes $(C g$-defm) display two structures, (i) two exons separated by a unique intron [32], a genomic organization similar to that of the mussel and scorpion defensin genes [34], and (ii) three exons separated by two introns. Hemocyte defensin genes (Cg-defhs) only display the latter structure, in which the second intron separates the two last residues of the mature peptide apart from the rest of the sequence [35].

- Precursors. All oyster defensins are expressed as precursors consisting in a hydrophobic signal peptide (prepeptide) immediately followed by the 4.6-4.7 $\mathrm{kDa}$ cationic mature peptide $(\mathrm{p} I$ 8.5-8.7). The absence of specific sorting/retention signal suggests defensins are secreted outside the cells.

- Structure. Mollusk defensins are small (4-5 kDa) cationic molecules containing six to eight cysteine residues engaged in three to four intramolecular disulfide bridges. They are all predicted to contain an $\alpha$-helix linked to an antiparallel two-stranded $\beta$-sheet by disulfide bridges, making the so-called cysteine-stabilized $\alpha$-helix/ $\beta$-sheet motif $(\operatorname{Cs} \alpha \beta)$ [36]. The American oyster defensin (AEO) isolated from $C$. virginica [31] contains 6 cysteines whereas in $C$. gigas, only defensins with eight cysteines were found $[32,33,35]$. The tridimensional structure of a mantle defensin from $C$. gigas $(\mathrm{Cg}$-Defm) was solved, showing that the $\operatorname{CS} \alpha \beta$ motif is indeed stabilized by four disulfide 
bridges (cysteine pattern: $\mathrm{C}_{1-5} \mathrm{C}_{2-6} \mathrm{C}_{3-7} \mathrm{C}_{4-8}$ ) [32]. The fourth disulfide bridge is a unique feature from mollusk defensins. It has been proposed to be implicated in the stabilization of the mature peptide to the high osmolarity environment found in the sea water [37].

- Antimicrobial activities and mechanism of action. The C. virginica defensin was shown to be active against both Gram-positive and Gram-negative bacteria. Thus, in a so-called ultrasensitive radial diffusion assay (URDA), the Minimal Effective Concentration (MECs) of AEO were below $3.5 \mu \mathrm{M}$ [31]. Until now, native defensins could not be purified from $C$. gigas tissues in sufficient amounts to enable complete biochemical characterization and determine their spectrum of activity. Antibacterial and antifungal activities of $C g$-Defs were studied with recombinant peptides $[32,38]$. All oyster defensins were shown to be mainly active against Gram-positive bacteria against which they displayed low to very low minimal inhibitory concentrations (MICs) in the range of 0.01-6 $\mu \mathrm{M}$. Conversely, they did not display significant antimicrobial activity against Gram-negative bacteria including oyster pathogens ( $\mathrm{MICs} \geq 10 \mu \mathrm{M}$ ). This is likely due to their capacity to strongly inhibit peptidoglycan biosynthesis [38], which is readily accessible at the cell wall of Gram-positive bacteria and hidden by the outer membrane of Gram-negative bacteria. Studies on Staphylococcus aureus showed that antibacterial activity is observed in absence of membrane disruption and results from the high affinity binding of $C g$-Defs to the cell wall precursor lipid II [38]. Interestingly, at high concentrations (10 $\mu \mathrm{M}$ and above), $C g$-Defs can also present membrane-disruptive properties as observed against the Gram-negative Vibrio tasmaniensis LGP32 [39].

\section{1-3-2 Big defensins ( $C g$-BigDefs)}

Big defensins (BigDefs) are antimicrobial polypeptides $(8-11 \mathrm{kDa})$ only found in marine invertebrates (Arthropoda, Mollusca and Cephalochordata) [40]. They are cationic molecules with $p I$ ranging from 8.6 to 9.2. The first BigDef was purified from the hemolymph cells (amebocytes) of the horseshoe crab Tachypleus tridentatus (Chelicerata) [41]. In C. gigas oysters, BigDef homologues were identified more recently through a genome-wide transcriptomic study [40]. Oyster big defensins ( $C g$-BigDefs) form a diverse family of AMPs composed of three representative members, namely $C g$-BigDef1, $C g$-BigDef2 and $C g$-BigDef3. In $C$. gigas, $C g$ BigDef expression is restricted to hemocytes, both circulating and infiltrating oyster tissues.

- Gene organization. Each of the three $C g$-BigDefs is encoded by a separate gene. The genomic organization of $C g$-bigdef1 and $C g$-bigdef2 genes is similar, with two exons interrupted by a single intron. In contrast, in $\mathrm{Cg}$-bigdef3, additional intron and exon are observed upstream the first exon common to the other $C g$-bigdefs. In all $C g$-bigdef genes, the $\beta$-defensin domain is exclusively encoded by the last exon [40]. 
- Precursors. Oyster big defensins are expressed as prepropeptides, which start with a predicted 23residue signal peptide (prepeptide), followed by a propeptide region of 13 residues and a cationic 94- or 87-residue mature polypeptide of $10.7 \mathrm{kDa}(C g$-BigDef1), $9.8 \mathrm{kDa}(C g$-BigDef2) or $9.7 \mathrm{kDa}$ ( $\mathrm{Cg}$-BigDef3). Similarly, in the horseshoe crab, BigDef is produced as a precursor molecule that is further processed into a $8.6 \mathrm{kDa}$ mature polypeptide [41].

- Structure. The solution structure of the horseshoe crab BigDef is the only one available to date. It showed that big defensins are composed of an N-terminal globular and hydrophobic domain connected to a $\mathrm{C}$-terminal domain containing $\beta$-sheet structures and folded by three disulfide bridges. Interestingly, the arrangement of the disulfide bridges is identical to that of vertebrate $\beta$ defensins ( $\beta$-defensin domain: $\mathrm{C}_{1-5} \mathrm{C}_{2-4} \mathrm{C}_{3-6}$ ) [42]. Based on mass spectrometry data, it has been proposed that oyster big defensins undergo post-translational modifications like the conversion of the N-terminal glutamine residue of the native $C g$-BigDef1 into a pyroglutamic acid [40].

- Antimicrobial activities. The antimicrobial activities of oyster BigDefs have not been characterized to date. However, in another bivalve mollusk, Argopecten irradians, BigDefs were reported to be active against both Gram-positive and Gram-negative bacteria and fungi [43] as well as in the horseshoe crab T. tridentatus, where, the native BigDef was also shown to display a significant LPS-binding activity [41].

\section{1-3-3 Proline-rich peptides (Cg-Prps)}

Proline-rich AMPs (PrAMPs) have been identified in vertebrates including mammals and amphibians as well as invertebrates such as insects and crustaceans. They form a group of diverse peptides that display a high content in proline and arginine residues (typically from 25 to $50 \%$ ). They display short Pro-Arg motifs, which have been proposed to be implicated in their antimicrobial activity. PrAMPs are also characterized by their mode of action, which usually does not involve the lysis of bacterial membranes but rather the penetration into Gram-negative bacteria by translocating into the cytoplasm via a permease/transporter-mediated uptake. Thereby, many PrAMPs act by interfering with essential cellular functions intracellularly [44]. In C. gigas oysters, a cDNA sequence showing homologies to PrAMPs was identified as expressed in hemocytes [45]. A high number of $C g$-Prp (C. gigas proline-rich peptide) forms were then identified as expressed by oyster hemocytes. They display two lengths (16 or 18 amino acids), with shorter peptides differing from the original $C g$-Prp by the deletion of a conserved Pro-Arg motif [35]. Consequently, the original form was renamed as long $C g$-Prp $(C g$-lgPrp; $1.8 \mathrm{kDa})$ and the new form as short $C g$-Prp ( $C g$-stPrp; $1.5 \mathrm{kDa}$ ) [46]. $C g$-Prps are highly cationic peptides with a theorical $p I$ of 12-12.1.

- Gene organization. Cg-Prps are a multigenic family with genes containing or not an intron. The 
presence/absence of an intron is observed in the genes encoding both the long and short peptide forms.

- Precursors. PrAMPs from C. gigas (Cg-Prps) derive from 59-62 amino acid precursors composed of an N-terminal signal peptide followed by an acidic region (putative propeptide) and a C-terminal cationic proline-rich region, containing two repetitions of a Pro-Arg motif [45]. This organization is conserved in all precursors of $C g$-Prps [35].

- Antimicrobial activities. Native $C g$-Prps could not be purified from oyster hemocyte extracts until now. Therefore, synthetic $C g$-Prps were used to explore their spectrum of antimicrobial activity. Both long and short $C g$-Prps were poorly active against Gram-positive bacteria and were not active against Gram-negative bacteria. However, $C g$-lgPrp displayed strong synergy with $C g$-Defs and $C g$ BPI against both Gram-positive and Gram-negative bacteria [45,47]. The underlying mechanisms remain unexplored.

\section{1-3-4 Cg-Molluscidin}

Besides the well-known AMP families mentioned above, a novel antimicrobial peptide has been purified for the first time from the gills of $C$. gigas. It does not show sequence homology with already known AMPs. This $5.5 \mathrm{kDa}$ peptide, which shows a calculated $p I$ of 11.28 , was named $C g$ Molluscidin [48]. Cg-Molluscidin transcripts were found predominant in oyster mantle tissue, then in gills and other organs, but it is likely that Molluscidin could be expressed by infiltrating hemocytes. No data are yet available on gene organization of this new AMP.

- Precursor. Native Cg-Molluscidin (55 amino acids) was shown to derive from a precursor molecule by the only elimination of its N-terminal methionine. This precursor is devoid of signal peptide or anionic proregion. From the mass spectrometry data, the native $C g$-Molluscidin would not undergo any further posttranslational modification [48].

- Structure. The primary structure of $C g$-Molluscidin is characterized by a high percentage of two residues, Ala (15) and Lys (23). The sequence is organized in 10 dibasic residue repeats including Lysine-Lysine or Lysine-Arginine and separated by hydrophobic amino acids, Ala (15 amino acids), Val or Gly [48].

- Antimicrobial activities. Native $C g$-Molluscidin was shown to be active against both Grampositive bacteria in a so-called ultrasensitive radial diffusion assay (URDA). Under these conditions, the Minimal Effective Concentration (MECs) of $C g$-Molluscidin was in the range of 1.3-31.3 $\mu \mathrm{g} / \mathrm{mL}$ against Gram-positive bacteria and 0.4-2.3 $\mu \mathrm{g} / \mathrm{mL}$ against Gram-negative bacteria including Vibrio parahaemolyticus. No antifungal or hemolytic activities were recorded for $\mathrm{Cg}$ Molluscidin [48]. 


\section{1-3-5 Bactericidal/permeability increasing protein (Cg-BPI)}

Bactericidal/permeability-increasing proteins (BPIs) and lipopolysaccharide-binding proteins (LBPs) are components of the immune system that have been mainly characterized in mammals. Although highly similar (45\% sequence identity), only BPIs display antimicrobial activity. By genomic approaches, LBP/BPI-related genes have been found in a number of non-mammalian vertebrates, invertebrates like nematodes and mollusks, and protists [49]. A homologue of the human BPI (hBPI) protein with a calculated molecular mass of $50.1 \mathrm{kDa}$, was identified in $C$. gigas oysters by a screening of a hemocyte EST library [50]. $C g$-BPI expression is constitutive in oyster epithelia and induced by microbial challenge in oyster hemocytes [50]. More recently, a homolog of $C g$-BPI named $C g$-BPI2 was also identified in a $C$. gigas hemocyte EST library [51]. It shares $56.4 \%$ amino acid identity with $C g$-BPI. It was proposed to originate from $C g$-BPI by gene duplication but it would follow a distinct expression pattern [51]. To date, $C g$-BPI gene organization has not yet been determined.

- Precursors. $\mathrm{Cg}$-BPI is expressed as a precursor protein composed a 19-residue signal peptide followed by the mature protein [50]. $C g$-BPI2 displays the same organization of $C g$-BPI precursor, with a 22-residue signal peptide, followed by the mature protein [51].

- Structure. As deduced by molecular modeling, $C g$-BPIs display the typical structural features of hBPI with an $\mathrm{N}$ - and $\mathrm{C}$-terminal $\beta$-barrel type domains connected by a proline-rich central domain [50,51]. The N-terminal domain of $C g$-BPI contains the LPS-binding regions characterized in hBPI and the Lys and Arg residues required for LPS-binding. This domain also contains the cysteine bridge of hBPI at conserved position, three extra cysteine residues being identified (both in the Nand C-terminal domains) whose folding remains unknown [50].

- Antimicrobial activities and mechanism of action. The full-length recombinant $C g$-BPI was shown to be a monomeric protein $(50.1 \mathrm{kDa})$ highly active against the short-chain LPS Escherichia coli strain SBS363, against which it displayed bactericidal activity. It was 30 times less active against the long-chain LPS E. coli ML35. Consistent with its spectrum of activity directed against Gram-negative bacteria, recombinant $C g$-BPI displayed both LPS- and Lipid A-binding activities. Like hBPI, it permeabilized the cytoplasmic membrane of E. coli ML35 [50]. The activity of the recombinant $C g$-BPI2 N-terminal $\beta$-barrel domain was also shown to be exclusively active against Gram-negative bacteria [51]. Thus, like in human BPI, the N-terminal domain of C. gigas BPIs is sufficient for its antibacterial activity.

\section{1-3-6 Macrophage expressed gene 1- like (Cg-Mpeg1)}


Lastly, a macrophage expressed gene 1-like protein has been identified in C. gigas by a genomic approach (GenBank: EF627979; HQ228218) and proposed to have antimicrobial properties [52]. The $C g$-Mpeg1 $(81.8 \mathrm{kDa})$ is a member of the membrane attack complex and perforin (MACPF) protein superfamily, a large group of pore-forming proteins widely conserved in the animal kingdom from mammals to low vertebrates. $C g$-Mpeg1 shows $47-48 \%$ identity with three abalone (gastropod) Mpeg1 sequences [53] and, 39\% and 35\% identity with sequences from mammals and sponges, respectively [52]. $C g$-Mpeg1 would be constitutively expressed in various tissues of healthy oysters and $C g$-Mpeg1 transcripts were predominantly detected in gonads and gills [52]. Gene organization remains to be determined.

- Precursor. $C g$-Mpeg1 is encoded as a putative 752 amino acid precursor carrying an N-terminal signal peptide of 19 amino acids.

- Structure. The Cg-Mpeg1 mature protein is predicted to contain a membrane-attack complex/perforin (MAPCPF) domain and a C-terminal transmembrane segment [52].

- Antimicrobial activities. A sequence of $C g-\operatorname{Mpeg} 1$ including the MACPF domain has been expressed in E. coli system. The recombinant MACPF domain could inhibit the growth of both Gram-positive and Gram-negative bacteria including Vibrio alginolyticus [52]. It is unknown whether $C g$-Mpeg1 creates membrane damages in bacteria.

\section{1-5 Other antimicrobial molecules}

\section{1-5-1 Lysozymes}

Lysozymes are cationic hydrolytic enzymes wildly distributed in the animal kingdom and found in a variety of cells, tissues and secretions from bacteria to humans. After being considered for a long time as hydrolytic enzymes involved in the degradation of bacteria cell wall, lysozymes are now considered as antimicrobial proteins. Bivalve lysozymes are members of a large family of proteins, referred to as invertebrate-type lysozymes [54]. These enzymes are believed to be involved in host defense due to their lytic properties on the peptidoglycan, the major component of the bacterial cell wall. However, this property could also be used by some lysozymes for digestive functions in oysters [55,56]. In C. gigas, lysozyme activities were reported in gills, mantle and digestive diverticula [57], then different lysozymes sequences have been identified in $C$. gigas by genomic approaches. Three lysozyme cDNAs have been characterized in C. gigas. CGL-1, -2 and 3 are encoded by 530-536-bp cDNA sequences with an open reading frame of 429-bp deducing 142 amino acid residues [58,59]. The precursors carry an N-terminal signal peptide of 20 amino acids. Comparatively in $C$. virginica, $c v$-lysozyme 3 cDNA was identified as 663-bp sequence with a 564 
bp open reading frame encoding 187 amino acids [56]. A predicted signal peptide was 18 amino acid residues.

Three different genomic sequences coding for lysozymes can be found in C. gigas genome scaffolds (GenBank: JH816436, JH816734, JH819154), confirming that lysozymes comprise a multigenic family. Lysozyme expression has been detected and localized in digestive cells of digestive tubules, gills and mantle [56,58,60,61]. However, CGL-1 was shown to be differentially expressed in hemocytes following C. gigas infection with the pathogenic V. tasmaniensis LGP32 compared to a non-virulent one [62]. Besides, lysozyme activity has been shown to increase in hemolymph following a co-stimulation of LPS and an oyster recombinant tumor necrosis factor, $\mathrm{rCg}$-TNF1 [63]. Altogether, these results support a role of lysozyme in the oyster antimicrobial defenses, which requires to be further investigated. Indeed, based on in vitro activity of recombinant CGL-1 and -3, lysozymes seems to display a weak activity $(10-40 \mu \mathrm{g} / \mathrm{mL})$ specifically against Gram-positive bacteria.

\section{1-5-2 Cg-Ubiquitin}

Ubiquitin is a structurally conserved polypeptide found in almost all tissues of eukaryotic organisms that regulates several processes, the most widely recognized being protein degradation [64]. Thus, in an essential function, ubiquitin molecules are covalently attached to target proteins for their subsequent degradation via the proteasome. Several additional functions of vertebrate ubiquitins have been described, such as alteration of cellular location, stability or activity of the target proteins, and lately, antibacterial and antifungal activities $[65,66]$.

In oysters, the antimicrobial activity of ubiquitin has been recently reported [67]. $\mathrm{Cg}$ Ubiquitin was purified from acidified gill extracts of $C$. gigas. The polypeptide had a molecular weight of $8.4 \mathrm{kDa}$ and the $\mathrm{N}$-terminal region is identical to ubiquitin sequences reported from other species. $C g$-Ubiquitin transcripts were found to be expressed at high level in the mantle tissue, and to a lesser extent in gills, digestive gland, adductor muscle and labial palps [67]. $\mathrm{Cg}$-Ubiquitin is encoded as a 76 amino acid precursor fused to the ribosomal protein S27. The precursor included a six amino acid motif and three conserved lysine at the functional sites, which might participate in the formation of the ubiquitin-protease complex. $C g$-Ubiquitin also displays an 80 -amino acid carboxyl ribosomal protein S27 extension with a classical zinc finger motif [67]. By homology modeling, $C g$-Ubiquitin was deduced to display three secondary structural motifs, including three $\alpha$-helices and four $\beta$-strands separated by 7 loop regions. The C-terminal region of the $C g$-Ubiquitin mature polypeptide terminated with an Arg residue instead of a Gly-Gly doublet, characteristic of ubiquitin molecules in other species [67]. 
The purified $C g$-Ubiquitin was shown to be active against Gram-positive (MECs, 3.4, 7.8 and $40 \mu \mathrm{g} / \mathrm{mL}$ ) and Gram-negative bacteria (MECs, 1.9-12.0 $\mu \mathrm{g} / \mathrm{mL}$ ) using the ultrasensitive radial diffusion assay (URDA) developed by the authors. $C g$-Ubiquitin was bacteriostatic and did not permeabilize the bacterial membranes. No antifungal or hemolytic activities were observed for this polypeptide [67].

\section{1-5-4 Histones}

Histones play an essential architectural role in chromatin formation and their posttranslational modifications play a key role in gene regulation. Since 1942 [68], histones have also been shown to carry antimicrobial activities against a wide range of pathogens including Gramnegative and Gram-positive bacteria, fungi, virus and protozoa [69]. These proteins and their derivative peptides have shown a wide range of actions in antibacterial processes, including permeabilization of bacterial cell membrane, binding to bacterial DNA and/or RNA [69], and neutralization of the LPS toxicity [70]. Recently, H2B histones active against Gram-positive and Gram-negative bacteria strains have been isolated from the American oyster C. virginica [71]. Similarly, antimicrobial H1-delta and $\mathrm{H} 5$ histones have been purified from gills of $C$. gigas oysters injured or infected with the oyster pathogen $V$. tasmaniensis LGP32 [72]. They showed potent antimicrobial activities against several strains of Gram-positive and Gram-negative bacteria with MICs below $0.7 \mu \mathrm{M}$. Moreover, in response to infection by the protozoan parasite Perkinsus marinus, the abundance of $\mathrm{H} 4, \mathrm{H} 3.3$ and $\mathrm{H} 2 \mathrm{~B}$ histone transcripts increased in total extract of $C$. virginica gill tissue [73]. Similarly, histone $\mathrm{H} 4$ protein levels of $C$. virginica appeared to increase in hemocyte lysates and extracellular hemolymph of oysters infected by P. marinus [74]. Finally, antimicrobial histones of $C$. gigas accumulated in gills after injury and infection while they were absent from gills of unchallenged oysters [72]. This phenomenon correlated with a massive infiltration of hemocytes in the gills of infected oysters. Altogether, these studies support a role of histones in the antimicrobial defense of oysters. In agreement, release of extracellular histones was recently associated to a novel defense reaction in oyster referred to as ETosis [72] (see hemocyte reactions below).

\section{2- The antimicrobial response to infection}

The oyster antimicrobial response to infection needs to be reconsidered with the recent evidence that these bivalves naturally host diverse and abundant microbial communities [1] that may contribute to homeostasis, host protection and fitness in rapidly changing environments [75]. In a view similar to that of the interaction between the mammalian gut immune system and the 
abundant and diverse intestinal microbiota, the existence in oysters of an abundant microbiota associated to its epithelial surfaces and hemolymph questions about the modulation of the immune response. How is the equilibrium between bacteria and healthy oysters maintained? How are the oyster antimicrobial responses to opportunistic pathogens triggered and regulated? This leads to interesting tracks of reflection on the meaning of the "self versus non-self" theory in immunity [76] as well as on the fine-tuning of the interplay between the immune system and microbial organisms [77].

With the development of genomic studies, significant breakthroughs have been achieved in the identification of immune-related genes involved in defense mechanisms including recognition, cell signaling and cell communication that are known to activate or trigger cell-mediated reactions such as phagocytosis and production of antimicrobial molecules [5,62,78]. In particular, various elements of the Rel/NF-кB pathway have been described in oyster to be involved in immune response [79-82] (see also this issue $\mathrm{Yu}$ ), but still, we have no evidence that this pathway controls the regulation of oyster AMP expression. Nonetheless, differences have to be expected with the best described invertebrate, Drosophila, in terms of AMP regulation. Indeed, most of the knowledge on the signaling pathways controlling AMP expression has been acquired in Drosophila, which has an almost sterile hemolymph. Unlike in Drosophila, oyster AMPs appear to be predominantly constitutively expressed by hemocytes and epithelia. Moreover, the release of peptidoglycan and other microbe associated molecular patterns (MAMPs) by its abundant microbiota does not trigger an overwhelming of the immune system. To date, it is unknown whether those AMPs whose expression is induced by infection are induced by specific signals released by pathogens or by an overload of MAMPs in the oyster blood stream and tissues.

\section{2-1 Involvement of AMPs in the response to infection}

Whereas genomic approaches developed from various oyster tissues have greatly contributed to progress in the characterization of AMPs in oysters, it is noteworthy that these studies do not provide clear understanding on the regulation of expression and function of these immune effectors. As in oysters, most of the known AMP families are expressed by hemocytes that migrate to infection sites and infiltrate tissues [47], monitoring AMP expression in tissues, i.e. differentiating AMP transcription/translation in tissues from infiltration of tissues by AMP-expressing hemocytes, is a particularly challenging task that requires the use of immunohistochemistry and/or in situ hybridization. Currently, such data are available for defensins, big defensins, Prps and BPI, while, to date, Mpeg-1 and Molluscidin expression has only been monitored in tissue extracts (usually by quantitative PCR). 
AMPs in healthy oysters. In oysters, antimicrobial proteins and peptides are mainly constitutively expressed (Table 1). By using in situ hybridization Cg-defhs, Cg-prps and Cg-bigdef3 were shown to be expressed in hemocytes where, comparatively, transcripts of $C \mathrm{~g}$-BPI and $C g$ Bigdef1 and -2 were barely detected. $C g$-defm was expressed in mantle only while $C g$-bpi was expressed in epithelia of a broad series of organs [47]. Besides, Cg-molluscidin transcripts have been detected by PCR in mantle, gills and labial palps and at lower levels in digestive glands and adductor muscles of healthy oysters, but no data is available on hemocytes [48]. Finally, Cg-mpeg 1 would be constitutively expressed in the same tissues, the highest level of transcripts being detected in gills and gonads, then in digestive glands followed by the mantle, heart, adductor muscle and hemocytes [52].

To date, only few data are available on the subcellular localization of AMPs in hemocytes and tissues. $C g$-BPI and $C g$-Prps appear to be stored in cytoplasmic granules in same hemocytes where $\mathrm{Cg}$-Defhs are also immunocolocalized but uniformly distributed throughout the cytoplasm [32,47]. We recently showed that $40 \%$ of total hemocytes express $C g$-BPI, although different subsets of hemocytes express it at different levels (Figure 1). A subset corresponding to $40 \%$ of the hyalinocytes express $\mathrm{Cg}$-BPI at a low level and the protein is stored in particular vesicles localized in the Golgi apparatus region. In granulocytes, two different subsets can be identified based on $\mathrm{Cg}$ BPI expression. Most granulocytes express $C g$-BPI (65\%) with 30\% of them expressing it at a high level, and the protein is stored in large cytoplasmic granules in those cells (see Figure 1 and [47]).

AMPs in diseased and injured oysters. Various infectious and non-infectious challenges have been used to study AMP expression in oysters. Still, most often, injection of bacteria and injury has been used, respectively. By using in situ hybridization and qPCR, Cg-bpi and Cg-bigdefl and -2 were shown to be strongly induced by bacterial challenge in hemocytes [40,50]. Apart from them, $C g$-Mpeg1 was reported to be induced in this tissue, but weakly and only 6 hours after challenge [52]. On the contrary, as described above, expression of Cg-defhs and Cg-bigdef3 is not regulated in response to microbial challenge. Injured or infected tissues often show an increase in AMP transcript abundance consistent with their immune function. This increase can be due to the accumulation of AMP-expressing hemocytes. This has been particularly well illustrated for the $C g$ Defh-expressing hemocytes following an injection of sea water or bacteria into the oyster adductor muscle. The decrease in $C g$-Defh transcript abundance in circulating hemocytes was seen to be concomitant with an increase in their abundance at the site of injury, and to a lesser extent in surrounding tissues of the mantle and gills [47,50]. Interestingly, neither $C g$-BPI nor $C g$-Prpexpressing hemocytes would migrate towards the injection site. Indeed, $C g$-Prp expression seems to decrease in both, circulating and infiltrating hemocytes after a vibrio challenge [47]. $\mathrm{Cg}$ - 
Molluscidin transcript abundance have been reported to increase significantly in gills after microbial challenge with vibrios [48]. However, it is still unknown whether this is due to hemocyte infiltration or tissue expression. Discrepancy in AMP expression and localization following challenge can be observed in literature, mainly due to the omission of the migratory behavior of hemocytes and their abilities to infiltrate oyster tissues where they may aggregate.

Studies on AMP family expression have revealed the existence of different chemotactic behavior among hemocyte populations or between hemocyte developmental stages. Most of all, they highlight (i) the major role of the hemocyte populations in the AMP-mediated defense reactions and (ii) the complexity of this tissue in terms of functions and mechanisms of regulation of immune-related gene expression, which could be related to existence of various cell lineages. As an example, while, upon infection, constitutively expressed AMPs like $C g$-Defhs and $C g$-Bigdef3 are transported through the migratory behavior of hemocytes, $C g$-BPI and $C g$-Bigdef1 and -2 are strongly transcribed in hemocytes infiltrating tissues [40,50].

Therefore, hemocytes must be seen as vehicles that drive given AMPs toward damaged or infected organs where other AMPs like $C g$-Defm and $C g$-BPI are constitutively expressed. Thus, AMP colocalization may occur in epithelia of various organs contributing to synergism and to local active antimicrobial reaction. One can assume that synergism takes place also during phagocytosis for AMPs colocalized in some hemocyte populations as reported for $C g$-Defhs and $C g$-Prps, and for $C g$-Defhs and $C g$-BPI [45,47]. Indeed, strong synergism against the oyster pathogen $V$. tasmaniensis LGP32 was reported between hemocyte defensins ( $C g$-Defh1 and -2) and mantle defensin $C g$-Defm [47].

One striking feature of oyster antimicrobial defense to infection or injury is the absence of systemic humoral reaction characterized by the massive release or secretion of AMPs into the blood stream. In contrast, great amounts of AMPs are released following microbial infection in many invertebrates. In insects, microorganisms induce the expression of AMPs in epithelial cells and in the fat body, which are immediately and massively secreted in the blood stream [83]. In shrimp, the constitutively expressed penaeidins, which are stored in cytoplasmic granules, are released through an original phenomenon of intracellular degranulation followed by the lysis of the hemocytes [84]. In mussels, AMPs are released by active degranulation process [85].

The lack of evidence of AMP release in oysters strongly contrasts with their detection in cells and tissues. Such low concentrations of extracellular AMPs support the hypothesis of a controlled antimicrobial defense that enables oysters to host and interact with a beneficial microbiota in its hemolymph and body. It also suggests that AMPs function primarily in hemocytes or epithelial cells. From our current knowledge, the AMP-mediated control of pathogens in oysters is likely 
based on phagocytosis as described for human neutrophil peptides [86] or mussel mytilins [87] in a process that benefits from the hemocyte migratory behavior. Besides, the constitutive expression of AMPs at surface epithelia may contribute to control the commensal microbiota and confer protection against potential pathogens [88].

\section{2-2 Hemocyte reactions}

Hemocytes play a central role in the oyster defense, they are able to respond to pathogen invasion or tissue damages through chemotaxis and phagocytosis [15,17]. Their microbicidal activities are based not only on the production of antimicrobial peptides/proteins as discussed above $[32,40,50]$ but also on hydrolytic enzymes [89] and Reactive Oxygen Species (ROS) [90,91]. As described above, the very active recruitment of hemocytes is best highlighted by their massive infiltration in injured and/or infected tissues [15,72,92]. Hemocyte migration leads to a local concentration of immune effectors believed to prevent host tissue invasion [47].

Phagocytosis. One of the best described immune function of hemocytes is phagocytosis of microorganisms (Figure 2). The central role of phagocytosis in the immune response has been evidenced by (i) the overrepresentation of transcripts of phagocytosis-related genes in hemocytes of oysters surviving infections by virulent vibrio strains as compared to oysters receiving the same doses of a non-virulent strain of vibrio [62], and (ii) by the identification of pathogenic vibrios that either avoid phagocytosis like $V$. aestuarianus 01/32 [93] or resist intracellular killing like $V$. tasmaniensis LGP32 [14]. The phagocytosis avidity of hemocytes is enhanced by opsonisation of the microorganisms by plasma proteins like $C g$-EcSOD, which promotes $\beta$-integrin-mediated phagocytosis [14]. Concomitant to phagocytosis, hemocytes generate a significant respiratory burst resulting in the production of a variety of intermediate ROS [72,90,91], in a major microbicidal reaction in oysters. The production of ROS relies on NADPH oxidases as well as a transmembrane enzyme termed DUOX for (DUal OXidase) that were evidenced in the $C$. gigas genomic resource database [94]. The expression of a DUOX-like gene in hemocytes was associated to a successful response of oysters against virulent vibrios [62].

After engulfment of microorganisms, the phagosome undergoes maturation with acidification and sequential fusion with endosomal and lysosomal compartments including granules, which contain diverse families of antimicrobial peptides/proteins $[45,47]$. The release into the phagosome of microbicidal compounds leads to the rapid neutralization/degradation of the engulfed microorganisms. Among the hydrolytic enzymes that are released into the maturing phagosome, lysozymes are known play an important role in microbial destruction due to their lytic properties on 
the peptidoglycan of the bacteria cell wall [95]. Although unknown to date, it is likely that AMPs and lysozymes stored in hemocyte cytoplasmic granules are delivered to the phagosome to kill phagocytosed bacteria.

Extracellular trapping through ETosis. Recent studies have shown that phagocytes from metazoans can control microbes through the release of DNA extracellular traps (ETs) carrying antimicrobial peptides and histones (Figure 2). Antimicrobial activities of histones have been described since 1942, but the mechanisms facilitating histone release has long remained unidentified. In 2004 Brinkmann et al. described a new antimicrobial mechanism relying on the release by mammalian neutrophils of extracellular DNA networks carrying histones and granular antimicrobial proteins including AMPs and hydrolases [96,97]. Those ETs are able to entrap and eventually kill bacteria, fungi, parasites and viruses [96,98,99]. ET formation depends on ROS production [100], and can be induced by different immunological stimuli including microbeassociated molecular patterns or host inflammatory mediators associated with tissue damage [96,100]. This phenomenon of cell death responding to infection or damage was referred to as ETosis.

Evidence of ETs in the defense of invertebrates including C. gigas oysters in only recent [72]. In 2008, a first report on the insect Galleria mellonella suggested a role of extracellular nucleic acids in the immune response of invertebrates [101]. Three recent studies on mollusks, crustaceans and cnidarians demonstrated the actual role of ETs in the immune response of marine invertebrates and identified ETosis as a very ancient and evolutionary conserved host defense reaction. In oysters, hemocytes were shown to form ETs associated with antimicrobial histones, rapidly after an exposition to diverse microbial agents or tissue damage both in vitro and in vivo [72]. Similar to vertebrate neutrophils, the formation of ETs by the oyster hemocytes was dependent on the production of ROS [102]. However, unlike in other species, PMA failed to trigger the oxidative burst and the formation of ETs by oyster hemocytes. While in vertebrates ETs are formed mostly by neutrophils, the population of oyster hemocytes able to form ETs in oysters remains to be identified.

\section{3- Unexplored functions of oyster AMPs}

Until now, the main host defense function recognized for AMPs has been the direct killing of microorganisms. However, over the past years, an abundant literature has shown that AMPs from vertebrates support a broad series of immune functions. Indeed, there is new evidence that they also display immunomodulatory functions involving chemotactic activities, induction and/or inhibition of cytokine production, wound healing and modulation of immune cells responses (reviewed in 
[103]). Still, little attention has been paid to the multiple functions of invertebrate antimicrobial peptides. There are already some evidences that mollusk AMPs can serve immune functions other than antibacterial/antifungal, like myticin C from Mytilus galloprovincialis, which has antiviral and chemotactic activities [104] in addition to the known antibacterial properties of myticins [105]. However, these functions have been explored in heterologous systems and their role in mollusk defense has not been investigated to date. We review here a series of functions that deserve to be explored to better characterize the immune functions of oyster AMPs.

Antiviral properties. Antiviral activities of invertebrate AMPs have been poorly explored in homologous systems mainly due to the lack cell lineages facilitating the design of antiviral assays. At this stage it is still unknown whether oyster AMPs can be antiviral. Interestingly, plectasin from the fungus Pseudoplectania nigrella, which shares a similar structure and mechanism of antibacterial action with $C g$-Defs $[38,106]$ was recently found to have antiviral activity. Studies on the antiviral properties of oyster defensins should be highly motivated by the severe viral diseases affecting oysters [107].

Antifungal properties. Many $\operatorname{Cs} \alpha \beta$ defensins from invertebrates and plants have been characterized for their antifungal properties [108]. Some are strictly antifungal, while others like $C g$-Defs seem to be potent antibacterials [47] with antifungal properties [32]. Antifungal properties have also been evidenced for other families of antimicrobials. For instance, the BPI antimicrobial protein from the gastropod mollusk Biomphalaria glabrata was recently proposed to protect the snail eggs from fungal infections [109]. The antifungal properties of $C g$-BPI remain to be studied.

Chemokine activities. Until the recent study on myticin C [104], little attention had been paid to the chemotactic properties of mollusk AMPs. However, diverse families of cysteine-rich AMPs can act as chemokines [110]. It is therefore tempting to speculate on the potential chemotactic activity of oyster defensins. Such an activity should also be investigated for $C g$-BPI. Indeed, it has been shown that cellular responses are induced by human LBP, which is highly similar to BPI in terms of structure and LPS-binding properties. In particular, it participates in the acute mobilization of circulating neutrophils to sites of tissue injury [111]. Such an activity could also contribute to the massive migration of hemocytes to sites of infection/injury in oyster.

Opsonization. Finally, an important function to be tested for mollusk AMPs is their capacity to promote phagocytosis by oyster hemocytes. Indeed, AMPs have the capacity to bind to the surface of bacteria and this process could enhance hemocyte phagocytosis. This has been shown for hBPI, which opsonizes bacteria, enhancing neutrophil phagocytosis [112]. As already shown for the extracellular superoxide dismutase $C g$-EcSOD [14], such an opsonin activity deserves further 
investigation among oyster AMPs.

\section{4- Genetic view of oyster antimicrobial defense}

\section{4-1 AMP sequence diversity and evolution}

Genomic structural organization. Whereas C. gigas genome has been recently sequenced [78], our knowledge about oyster AMP gene organization in oyster genome remains quite limited. Numerous DNA and RNA sequences have been characterized among the different AMP families (Table 3), revealing a great intra- and inter-individual diversity. $C g$-Def family appears to be the most diversified with 89 different mRNA sequences and 25 gDNA ones, available on GenBank (Table 3). However, it is noteworthy that we failed to evidence in the published database, OysterBase (http://www.oysterdb.com/), any full sequences of AMP encoding genes, but only mRNA sequences were found. Because whole $C$. gigas genome has been sequenced from one individual oyster [78], it is likely that the high level of diversity in terms of sequences and genetic structure variation (see below) contribute to difficulties for AMP sequence annotation. To date, it has been shown that $C g$-Defs, $C g$-Prps and $C g$-BigDefs are the products of multigenic families displaying a variety of gene structures and gene copy number variations. The number of $C g$-def gene copies was shown to be highly variable (14-53 copies) among individual oysters as well as for Cg-prp which displays from 4 to 18 gene copy numbers according to individuals $[35,113]$. The genomic structural organization of oyster AMP families remains a vast domain to be investigated.

Phylogenetics. Although sharing similar nomenclature, oyster defensins ( $C g$-Defs) and big defensins ( $\mathrm{Cg}$-BigDefs) have no clear phylogenetic relationships to each other (Figure 3 ). Indeed, $C g$-Defs are cysteine-rich peptides containing a $\operatorname{CS} \alpha \beta$ (cysteine-stabilized $\alpha \beta$ ) motif widespread in invertebrate defensins, like in arthropods and mollusks, but also in fungi and plants, and, remarkably, in toxins from scorpions [27,114]. However, the presence of eight cysteine residues was only reported in bivalve mollusk species $[30,32,33]$. This common structural fold strongly suggests there is a common ancestor to those different molecules, which has further evolved towards different functions, from toxins to antibacterials (fungi and mollusk defensins), antifungals (plant defensins), and as more recently shown antivirals (fungi defensins) [115]. On the other hand, invertebrate big defensins, including $C g$-BigDefs, are more related to the $\beta$-defensins from vertebrates [40]. Indeed, in vertebrates, defensins adopt a three-stranded antiparallel $\beta$-sheet structure which is connected by a pairing of 6 cysteine residues. The cysteine paring of invertebrate big defensins is similar to that of vertebrate $\beta$-defensins but totally differs from that found in the $\mathrm{CS} \alpha \beta$ motif. Importantly, this cysteine paring is similar in invertebrate big defensins and vertebrate 
$\beta$-defensins. It was recently proposed that vertebrate $\beta$-defensins originate from invertebrate big defensins [116].

Sequence diversity. In the last years, high levels of sequence polymorphism were reported to be characteristic of several immune genes from invertebrates [117]. A number of studies into the origin and evolution of innate immune molecules evidenced numerous mechanisms of diversification and directional selection pressures over these genes, related to adaptive molecular evolution [118]. In C. gigas, high levels of sequence diversity have been detected for some oyster AMP families, notably $C g$-Defs and $C g$-Prps [35]. Phylogenetic analyses showed that $C g$-Defs and $C g$-Prps sequences were clustered into distinct groups forming clearly structured phylogenies. For $C g$-Defs, three separate but constraint groups in which the three original forms where the most representatives are observed, while $C g$-Prp phylogeny showed more diverse groups suggesting an ongoing or recent process of neo- or sub-functionalization. From the same study, the diversity of $C g$-BPI sequences was shown to be less diverse when compared to the peptides, but the finding of a new variant of $C g$-BPI suggests the existence of a greater diversity than previously thought [51]. Furthermore, $C g$-BigDefs have been shown to display a diversity of sequences for the three of their members, presenting several isoforms of $C g$-BigDef-1, -2 and -3 variants [40].

The variability on the sequences of $C$. gigas AMPs appears to be generated by a combination of different genetic mechanisms previously described in the diversification of several antimicrobial molecules in Drosophila [119]. The rapid evolution of AMPs is well documented [120-122] and suggests that hosts exposed to diverse pathogens may evolve a broader repertoire of antimicrobials that enhance their defensive potential [123]. The rapid evolution of AMPs has been related with the general hypothesis of co-evolution or "arms race". In this theory, pathogens evolve continuously to escape from the immune response of hosts and, consequently, the immune system of hosts evolves to improve new barriers against pathogens [124]. Thus, it appears that oyster AMPs could be under strong selective forces shaping their sequence variations. This is supported by evolutionary analyses which revealed several negatively and positively selected sites for $C g$-Defs and $C g$-Prp [35]. Evidences of diversification in oyster AMPs also motivate the search for novel immune functions (neo-functionalization). It is indeed reasonable to speculate that such small and stable molecules, capable to resist to proteolysis in body fluids and tissues, are ideal candidates to mediate immune functions and are therefore the subject of intense selective pressures in the plastic association between the oyster and its microbiota.

\section{4-2 Individual polymorphism of gene expression and genetic structural variation}


The recent progress in genomics has opened new perspectives for exploring the oyster immune system. On the one hand, the first sequencing of C. gigas genome [78] and various transcriptomic studies allowed to identify a vast range of potential effectors and key actors of oyster immunity [62,94,125-127]. On the other hand, the development of genomic technologies such as high throughput RT-qPCR analyses allowed to explore the expression of numerous immune-related genes at the individual levels revealing an extraordinary polymorphism in basal expression of some of them in this species [128]. Indubitably, analyses performed at individual level may give new light on the genetic bases of oyster immune response and reveal its diversity and complexity. From these studies it is also clear that AMP-encoding genes show a great inter-individual variability of expression, as shown for Cg-defhs, Cg-prps, Cg-bpi and Cg-bigdefs [40,113,129].

It is known that gene expression polymorphism may result from epigenetic modifications or genetic structural variation such as gene Copy Number Variation (CNV). CNV is a type of polymorphism characterized by differences in the number of copies of a particular gene in the genotype of an individual. CNV can be associated to variable phenotypes, including susceptibility to diseases [130]. In oysters, CNV has been evidenced for the AMP-encoding genes $C g$-defs and Cg-prps with mean values of 18 and 48 gene copies respectively, whereas Cg-bpil has been found encoded by a single gene copy in all the individuals analyzed [35]. However, until now, the number of gene copies of $C g$-bpi2 and other oyster antimicrobials $(C g$-BigDefs, $C g$-Molluscidin and $C g$ Mpeg1) in individual oysters remains unknown. In a recent work, CNV has been correlated to the variability of AMP gene expression in oysters. For $C g$-defs, a positive correlation was found with variation of 14 to 48 gene copies among 14 individuals analyzed, whereas for Cg-prps, the variation ranged from zero to 18 copy numbers [113].

Noteworthy, inter-individual variability has been observed in the basal expression of $C g$ bigdefs using high throughput RT-qPCR analyses. Among 163 individual oysters, variability in basal gene expression reached up to 30, 27 and 7-fold for $C g$-BigDef1, $C g$-BigDef2 and $C g$ BigDef3, respectively. In addition, $C g$-BigDef expression could not be detected in 39 individuals. Further analyses at genome level revealed that this lack of expression was likely associated to the absence of encoding Cg-bigdef sequences [129] as previously observed for Cg-prps [113]. In such an extreme case of CNV, known as Presence-Absence Variations (PAV), large DNA segment present in some individuals can be entirely missing in others [131]. PAV is known in humans but also in plants for which the genetic diversity has been exploited for domestication. In humans, PAV has been described for the DEFA3 gene that encodes the human neutrophil peptide-3 (HNP-3) [132]. The presence of the encoding gene is variable depending on the human geographical populations and this variability has been suspected to be implicated with differences of susceptibility to 
infectious diseases [133]. In a larger extent, CNV has been associated to disease susceptibility particularly in the case of human defensins $[134,135]$.

To date, there are no evidences about a possible impact of such structural genome variations on the oyster susceptibility to infectious diseases. No relationship was observed between the Presence-Absence of Cg-bigdefs and the capacity of the oysters to survive experimental Vibrio infections [129]. In plants, it is assumed that PAVs may generate new pathogen resistances but most of all that it could contribute to individual adaptation to environmental stresses [136].

\section{5- Conclusions}

From the recent results and knowledge we reviewed here, the role of AMPs in the oyster immune system must be reconsidered taking into account that oysters must be seen as an organism associated to a microbiota. In such a context where the oyster can host an abundant and beneficial microbiota, AMPs cannot be considered only as repressive weapons. It is likely that in oyster, where AMPs are present at low concentrations [46], they are primarily involved in unexplored immune functions.

We have now evidences that the oyster antimicrobial defense is characterized by local responses ensured by hemocytes instead of systemic or humoral response as shown in other invertebrates. With their great capacity to move and infiltrate all oyster tissues and organs, the hemocytes, which carry AMPs and other immune effectors, may provide monitoring and immediate response to damages or injuries (Figure 2). The mechanisms that underlie hemocyte communication, recruitment and their activation remain largely unknown and the potential role of AMPs in such immune modulatory functions requires a particular attention.

One major advance over the past years is the evidence in $C$. gigas of a great AMP sequence diversity and extraordinary polymorphism of basal AMP gene expression among individuals. The relationship between the AMP gene expression level and genome structural variations such as gene copy number or presence/absence variation has been highlighted for the first time in an invertebrate. These results open indubitably new perspectives for investigating the oyster immune system and in particular the role that antimicrobials may play in the interaction of the immune system with the oyster commensal microbiota (from mutualists to pathogens) and the capacity of the oyster metaorganism (the oyster and its associated microbiota) to survive infections or diseases. 


\section{References}

[1] Lokmer A, Mathias Wegner K. Hemolymph microbiome of Pacific oysters in response to temperature, temperature stress and infection. ISME J 2014;9:670-82. doi:10.1038/ismej.2014.160.

[2] Wendling CC, Batista FM, Wegner KM. Persistence, seasonal dynamics and pathogenic potential of Vibrio communities from Pacific oyster hemolymph. PLoS One 2014;9:e94256. doi:10.1371/journal.pone.0094256.

[3] Lemire A, Goudenège D, Versigny T, Petton B, Calteau A, Labreuche Y, et al. Populations, not clones, are the unit of vibrio pathogenesis in naturally infected oysters. ISME J 2015. doi:10.1038/ismej.2014.233.

[4] Desriac F, Le Chevalier P, Brillet B, Leguerinel I, Thuillier B, Paillard C, et al. Exploring the hologenome concept in marine bivalvia: haemolymph microbiota as a pertinent source of probiotics for aquaculture. FEMS Microbiol Lett 2014;350:107-16. doi:10.1111/15746968.12308.

[5] Schmitt P, Duperthuy M, Montagnani C, Bachère E, Destoumieux-Garzón D. Immune responses in the Pacific oyster Crassostrea gigas: an overview with focus on summer mortalities. In: Qin J, editor. Oysters, Nova Science Publishers; 2012, p. 227-73.

[6] Petton B, Pernet F, Robert R, Boudry P. Temperature influence on pathogen transmission and subsequent mortalities in juvenile pacific oysters Crassostrea gigas. Aquac Environ Interact 2013;3:257-73. doi:10.3354/aei00070. 
[7] Samain JF, Dégremont L, Soletchnik P, Haure J, Bédier E, Ropert M, et al. Genetically based resistance to summer mortality in the Pacific oyster (Crassostrea gigas) and its relationship with physiological, immunological characteristics and infection processes. Aquaculture 2007;268:227-43. doi:10.1016/j.aquaculture.2007.04.044.

[8] Bachère E, Chagot D, Grizel H. Separation of Crassostrea gigas hemocytes by density gradient centrifugation and counterflow centrifugal elutriation. Dev Comp Immunol $1988 ; 12: 549-59$.

[9] Luo M, Ye S, Xu T, Wu X, Yang P. Molecular characterization of a novel tetraspanin from the oyster, Crassostrea ariakensis: variation, localization and relationship to oyster host defense. Fish Shellfish Immunol 2012;33:294-304. doi:10.1016/j.fsi.2012.05.009.

[10] Itoh N, Xue Q-G, Schey KL, Li Y, Cooper RK, La Peyre JF. Characterization of the major plasma protein of the eastern oyster, Crassostrea virginica, and a proposed role in host defense. Comp Biochem Physiol B Biochem Mol Biol 2011;158:9-22. doi:10.1016/j.cbpb.2010.06.006.

[11] Scotti PD, Dearing SC, Greenwood DR. Characterisation of cavortin, the major haemolymph protein of the Pacific oyster (Crassostrea gigas). New Zeal J Mar Freshw Res 2007;41:91101. doi:10.1080/00288330709509898.

[12] Green TJ, Dixon TJ, Devic E, Adlard RD, Barnes AC. Differential expression of genes encoding anti-oxidant enzymes in Sydney rock oysters, Saccostrea glomerata (Gould) selected for disease resistance. Fish Shellfish Immunol 2009;26:799-810. doi:10.1016/j.fsi.2009.03.003. 
[13] Gonzalez M, Romestand B, Fievet J, Huvet A, Lebart M-C, Gueguen Y, et al. Evidence in oyster of a plasma extracellular superoxide dismutase which binds LPS. Biochem Biophys Res Commun 2005;338:1089-97. doi:10.1016/j.bbrc.2005.10.075.

[14] Duperthuy M, Schmitt P, Garzón E, Caro A, Rosa RD, Le Roux F, et al. Use of OmpU porins for attachment and invasion of Crassostrea gigas immune cells by the oyster pathogen Vibrio splendidus. Proc Natl Acad Sci U S A 2011;108:2993-8. doi:10.1073/pnas.1015326108.

[15] Bachère E, Gueguen Y, Gonzalez M, de Lorgeril J, Garnier J, Romestand B. Insights into the anti-microbial defense of marine invertebrates: the penaeid shrimps and the oyster Crassostrea gigas. Immunol Rev 2004;198:149-68.

[16] Hine P. The inter-relationships of bivalve haemocytes. Fish Shellfish Immunol 1999;9:36785. doi:10.1006/fsim.1998.0205.

[17] Cheng T. Invertebrate blood cells. In: Ratcliffe N, Rowley A, editors. Invertebr. blood cells, New York: Academic Press; 1981, p. 233-301.

[18] SuJung C, SuMin T, HsinYiu C. Morphological characterization via light and electron microscopy of the hemocytes of two cultured bivalves: a comparison study between the hard clam (Meretrix lusoria) and Pacific oyster (Crassostrea gigas). Zool Stud 2005;44:144-52.

[19] Aladaileh S, Nair S V, Birch D, Raftos D a. Sydney rock oyster (Saccostrea glomerata) hemocytes: morphology and function. J Invertebr Pathol 2007;96:48-63. doi:10.1016/j.jip.2007.02.011.

[20] Rebelo MDF, Figueiredo EDS, Mariante RM, Nóbrega A, de Barros CM, Allodi S. New insights from the oyster Crassostrea rhizophorae on bivalve circulating hemocytes. PLoS One 2013;8:e57384. doi:10.1371/journal.pone.0057384. 
[21] Tirapé A, Bacque C, Brizard R, Vandenbulcke F, Boulo V. Expression of immune-related genes in the oyster Crassostrea gigas during ontogenesis. Dev Comp Immunol 2007;31:85973. doi:10.1016/j.dci.2007.01.005.

[22] Gree T. Master regulator unmasked. Nature 1996;383:575.

[23] Kissa K, Herbomel P. Blood stem cells emerge from aortic endothelium by a novel type of cell transition. Nature 2010;464:112-5. doi:10.1038/nature08761.

[24] Bertrand JY, Giroux S, Golub R, Klaine M, Jalil A, Boucontet L, et al. Characterization of purified intraembryonic hematopoietic stem cells as a tool to define their site of origin. Proc Natl Acad Sci U S A 2005;102:134-9. doi:10.1073/pnas.0402270102.

[25] Jemaà M, Morin N, Cavelier P, Cau J, Strub J-M, Delsert C. Adult somatic progenitor cells and hematopoiesis in oyster. J Exp Biol 2014. doi:10.1242/jeb.106575.

[26] Cuénot L. Études sur le sang et les glandes lymphatiques dans la série animale. Arch Zool Expérimentale Générale 1891;2:13-90.

[27] Bulet P, Stöcklin R, Menin L, Stocklin R. Anti-microbial peptides: from invertebrates to vertebrates. Immunol Rev 2004;198:169-84. doi:10.1111/j.0105-2896.2004.0124.x.

[28] Brogden KA. Antimicrobial peptides: pore formers or metabolic inhibitors in bacteria? Nat Rev Microbiol 2005;3:238-50. doi:10.1038/nrmicro1098.

[29] Charlet M, Chernysh S, Philippe H, Hetru C, Hoffmann JA, Bulet P. Isolation of several cysteine-rich antimicrobial peptides from the blood of a mollusc, Mytilus edulis. J Biol Chem 1996;271:21808-13. doi:10.1074/jbc.271.36.21808. 
[30] Hubert F, Noel T, Roch P. A member of the arthropod defensin family from edible Mediterranean mussels (Mytilus galloprovincialis). Eur J Biochem 1996;240:302-6.

[31] Seo J-K, Crawford JM, Stone KL, Noga EJ. Purification of a novel arthropod defensin from the American oyster, Crassostrea virginica. Biochem Biophys Res Commun 2005;338:19982004. doi:10.1016/j.bbrc.2005.11.013.

[32] Gueguen Y, Herpin A, Aumelas A, Garnier J, Fievet J, Escoubas J-M, et al. Characterization of a defensin from the oyster Crassostrea gigas. Recombinant production, folding, solution structure, antimicrobial activities, and gene expression. J Biol Chem 2006;281:313-23. doi:10.1074/jbc.M510850200.

[33] Gonzalez M, Gueguen Y, Desserre G, de Lorgeril J, Romestand B, Bachère E. Molecular characterization of two isoforms of defensin from hemocytes of the oyster Crassostrea gigas. Dev Comp Immunol 2007;31:332-9. doi:10.1016/j.dci.2006.07.006.

[34] Froy O, Gurevitz M. Arthropod and mollusk defensins--evolution by exon-shuffling. Trends Genet 2003;19:684-7. doi:10.1016/j.tig.2003.10.010.

[35] Schmitt P, Gueguen Y, Desmarais E, Bachère E, de Lorgeril J. Molecular diversity of antimicrobial effectors in the oyster Crassostrea gigas. BMC Evol Biol 2010;10:23. doi:10.1186/1471-2148-10-23.

[36] Zhu S, Gao B, Tytgat J. Phylogenetic distribution, functional epitopes and evolution of the CSalphabeta superfamily. Cell Mol Life Sci 2005;62:2257-69. doi:10.1007/s00018-0055200-6.

[37] Yang Y, Mitta G, Chavanieu A. Solution structure and activity of the synthetic four-disulfide bond Mediterranean mussel defensin (MGD-1). Biochemistry 2000;2:14436-47. 
[38] Schmitt P, Wilmes M, Pugnière M, Aumelas A, Bachère E, Sahl H-G, et al. Insight into invertebrate defensin mechanism of action: oyster defensins inhibit peptidoglycan biosynthesis by binding to lipid II. J Biol Chem 2010;285:29208-16. doi:10.1074/jbc.M110.143388.

[39] Duperthuy M, Binesse J, Le Roux F, Romestand B, Caro A, Got P, et al. The major outer membrane protein OmpU of Vibrio splendidus contributes to host antimicrobial peptide resistance and is required for virulence in the oyster Crassostrea gigas. Environ Microbiol 2010;12:951-63. doi:10.1111/j.1462-2920.2009.02138.x.

[40] Rosa RD, Santini A, Fievet J, Bulet P, Destoumieux-Garzón D, Bachère E. Big defensins, a diverse family of antimicrobial peptides that follows different patterns of expression in hemocytes of the oyster Crassostrea gigas. PLoS One 2011;6:e25594. doi:10.1371/journal.pone.0025594.

[41] Saito T, Kawabata S, Shigenaga T, Takayenoki Y, Cho J, Nakajima H, et al. A novel big defensin identified in horseshoe crab hemocytes: isolation, amino acid sequence, and antibacterial activity. J Biochem 1995;117:1131-7.

[42] Kouno T, Fujitani N, Mizuguchi M, Osaki T, Nishimura S. A Novel -Defensin Structure : A Potential Strategy of Big Defensin for Overcoming Resistance by Gram-Positive Bacteria 2008:10611-9.

[43] Zhao J, Song L, Li C, Ni D, Wu L, Zhu L, et al. Molecular cloning, expression of a big defensin gene from bay scallop Argopecten irradians and the antimicrobial activity of its recombinant protein. Mol Immunol 2007;44:360-8. doi:10.1016/j.molimm.2006.02.025. 
[44] Li W, Tailhades J, O’Brien-Simpson NM, Separovic F, Otvos L, Hossain MA, et al. Prolinerich antimicrobial peptides: potential therapeutics against antibiotic-resistant bacteria. Amino Acids 2014;46:2287-94. doi:10.1007/s00726-014-1820-1.

[45] Gueguen Y, Bernard R, Julie F, Paulina S, Delphine D-G, Franck V, et al. Oyster hemocytes express a proline-rich peptide displaying synergistic antimicrobial activity with a defensin. Mol Immunol 2009;46:516-22. doi:10.1016/j.molimm.2008.07.021.

[46] Schmitt P, Rosa RD, Duperthuy M, de Lorgeril J, Bachère E, Destoumieux-Garzón D. The Antimicrobial Defense of the Pacific Oyster, Crassostrea gigas. How Diversity may Compensate for Scarcity in the Regulation of Resident/Pathogenic Microflora. Front Microbiol 2012;3:160. doi:10.3389/fmicb.2012.00160.

[47] Schmitt P, de Lorgeril J, Gueguen Y, Destoumieux-Garzón D, Bachère E. Expression, tissue localization and synergy of antimicrobial peptides and proteins in the immune response of the oyster Crassostrea gigas. Dev Comp Immunol 2012;37:363-70. doi:10.1016/j.dci.2012.01.004.

[48] Seo J-K, Lee MJ, Nam B-H, Park NG. cgMolluscidin, a novel dibasic residue repeat rich antimicrobial peptide, purified from the gill of the Pacific oyster, Crassostrea gigas. Fish Shellfish Immunol 2013;35:480-8. doi:10.1016/j.fsi.2013.05.010.

[49] Krasity BBC, Troll JJ V, Weiss JP, McFall-Ngai MJ. LBP/BPI proteins and their relatives: conservation over evolution and roles in mutualism. Biochem Soc ... 2011;39:1039-44. doi:10.1042/BST0391039.LBP/BPI. 
[50] Gonzalez M, Gueguen Y, Destoumieux-Garzón D, Romestand B, Fievet J, Pugnière M, et al. Evidence of a bactericidal permeability increasing protein in an invertebrate, the Crassostrea gigas Cg-BPI. Proc Natl Acad Sci U S A 2007;104:17759-64. doi:10.1073/pnas.0702281104.

[51] Zhang Y, He X, Li X, Fu D, Chen J, Yu Z. The second bactericidal permeability increasing protein (BPI) and its revelation of the gene duplication in the Pacific oyster, Crassostrea gigas. Fish Shellfish Immunol 2011;30:954-63. doi:10.1016/j.fsi.2011.01.031.

[52] He X, Zhang Y, Yu Z. An Mpeg (macrophage expressed gene) from the Pacific oyster Crassostrea gigas: molecular characterization and gene expression. Fish Shellfish Immunol 2011;30:870-6. doi:10.1016/j.fsi.2011.01.009.

[53] Mah S a, Moy GW, Swanson WJ, Vacquier VD. A perforin-like protein from a marine mollusk. Biochem Biophys Res Commun 2004;316:468-75. doi:10.1016/j.bbrc.2004.02.073.

[54] Jollès P. From the discovery of lysozyme to the characterization of several lysozyme families. EXS 1996;75:3-5.

[55] Bachali S, Jager M, Hassanin A, Schoentgen F, Jollès P, Fiala-Medioni A, et al. Phylogenetic analysis of invertebrate lysozymes and the evolution of lysozyme function. J Mol Evol 2002;54:652-64. doi:10.1007/s00239-001-0061-6.

[56] Xue Q, Hellberg ME, Schey KL, Itoh N, Eytan RI, Cooper RK, et al. A new lysozyme from the eastern oyster, Crassostrea virginica, and a possible evolutionary pathway for i-type lysozymes in bivalves from host defense to digestion. BMC Evol Biol 2010;10:213. doi:10.1186/1471-2148-10-213.

[57] Takahashi K, Mori K, Nomura T. Occurrence and characterization of lysozyme from marine bivalves. Bull Japanese Soc Fish Sci 1986;52:863-8. 
[58] Itoh N, Okada Y, Takahashi KG, Osada M. Presence and characterization of multiple mantle lysozymes in the Pacific oyster, Crassostrea gigas. Fish Shellfish Immunol 2010;29:126-35. doi:10.1016/j.fsi.2010.02.027.

[59] Itoh N, Xue Q, Li Y, Cooper RK, La Peyre JF. cDNA cloning and tissue expression of plasma lysozyme in the eastern oyster, Crassostrea virginica. Fish Shellfish Immunol 2007;23:95768. doi:10.1016/j.fsi.2007.03.006.

[60] Matsumoto T, Nakamura AM, Takahashi KG. Cloning of cDNAs and hybridization analysis of lysozymes from two oyster species, Crassostrea gigas and Ostrea edulis. Comp Biochem Physiol B Biochem Mol Biol 2006;145:325-30. doi:10.1016/j.cbpb.2006.08.003.

[61] Itoh N, Takahashi KG. cDNA cloning and in situ hybridization of a novel lysozyme in the Pacific oyster, Crassostrea gigas. Comp Biochem Physiol B Biochem Mol Biol 2007;148:160-6. doi:10.1016/j.cbpb.2007.05.005.

[62] De Lorgeril J, Zenagui R, Rosa RD, Piquemal D, Bachère E. Whole transcriptome profiling of successful immune response to Vibrio infections in the oyster Crassostrea gigas by digital gene expression analysis. PLoS One 2011;6:e23142. doi:10.1371/journal.pone.0023142.

[63] Sun Y, Zhou Z, Wang L, Yang C, Jianga S, Song L. The immunomodulation of a novel tumor necrosis factor (CgTNF-1) in oyster Crassostrea gigas. Dev Comp Immunol 2014;45:291-9. doi:10.1016/j.dci.2014.03.007.

[64] Pickart CM, Eddins MJ. Ubiquitin: structures, functions, mechanisms. Biochim Biophys Acta 2004;1695:55-72. doi:10.1016/j.bbamcr.2004.09.019.

[65] Kieffer A, Goumon Y, Ruh O. The N-and C-terminal fragments of ubiquitin are important for the antimicrobial activities. FASEB J 2003. 
[66] Alonso S, Pethe K, Russell DG, Purdy GE. Lysosomal killing of Mycobacterium mediated by ubiquitin-derived peptides is enhanced by autophagy. Proc Natl Acad Sci U S A 2007;104:6031-6. doi:10.1073/pnas.0700036104.

[67] Seo J-K, Lee MJ, Go H-J, Kim G Do, Jeong H Do, Nam B-H, et al. Purification and antimicrobial function of ubiquitin isolated from the gill of Pacific oyster, Crassostrea gigas. Mol Immunol 2013;53:88-98. doi:10.1016/j.molimm.2012.07.003.

[68] Miller BF, Abrams R, Dorfman A, Klein M. Antibacterial properties of protamine and histone. Science (80- ) 1942;96:428-30. doi:10.1126/science.96.2497.428.

[69] Kawasaki H, Iwamuro S. Potential roles of histones in host defense as antimicrobial agents. Infect Disord Drug Targets 2008;8:195-205.

[70] Augusto LA, Decottignies P, Synguelakis M, Nicaise M, Le Maréchal P, Chaby R. Histones: a novel class of lipopolysaccharide-binding molecules. Biochemistry 2003;42:3929-38. doi:10.1021/bi0268394.

[71] Seo J-K, Stephenson J, Noga EJ. Multiple antibacterial histone H2B proteins are expressed in tissues of American oyster. Comp Biochem Physiol B Biochem Mol Biol 2011;158:223-9. doi:10.1016/j.cbpb.2010.11.011.

[72] Poirier AC, Schmitt P, Rosa RD, Vanhove AS, Kieffer-Jaquinod S, Rubio TP, et al. Antimicrobial histones and DNA traps in invertebrate immunity: evidences in Crassostrea gigas. J Biol Chem 2014;289:24821-31. doi:10.1074/jbc.M114.576546.

[73] Wang S, Peatman E, Liu H, Bushek D, Ford SE, Kucuktas H, et al. Microarray analysis of gene expression in eastern oyster (Crassostrea virginica) reveals a novel combination of 
antimicrobial and oxidative stress host responses after dermo (Perkinsus marinus) challenge. Fish Shellfish Immunol 2010;29:921-9. doi:10.1016/j.fsi.2010.07.035.

[74] Dorrington T, Villamil L, Gómez-chiarri M. Upregulation in response to infection and antibacterial activity of oyster histone H4. Fish Shellfish Immunol 2011;30:94-101. doi:10.1016/j.fsi.2010.09.006.

[75] McFall-Ngai M, Hadfield MG, Bosch TCG, Carey H V, Domazet-Lošo T, Douglas AE, et al. Animals in a bacterial world, a new imperative for the life sciences. Proc Natl Acad Sci U S A 2013;110:3229-36. doi:10.1073/pnas.1218525110.

[76] Pradeu T, Cooper EL. The danger theory: 20 years later. Front Immunol 2012;3:287. doi:10.3389/fimmu.2012.00287.

[77] Muraille E. Redefining the immune system as a social interface for cooperative processes. PLoS Pathog 2013;9:e1003203. doi:10.1371/journal.ppat.1003203.

[78] Zhang G, Fang X, Guo X, Li L, Luo R, Xu F, et al. The oyster genome reveals stress adaptation and complexity of shell formation. Nature 2012;490:49-54. doi:10.1038/nature11413.

[79] Zhang Y, He X, Yu F, Xiang Z, Li J, Thorpe KL, et al. Characteristic and functional analysis of toll-like receptors (TLRs) in the lophotrocozoan, Crassostrea gigas, reveals ancient origin of TLR-mediated innate immunity. PLoS One 2013;8:e76464. doi:10.1371/journal.pone.0076464.

[80] Zhang L, Li L, Zhang G. A Crassostrea gigas Toll-like receptor and comparative analysis of TLR pathway in invertebrates. Fish Shellfish Immunol 2011;30:653-60. doi:10.1016/j.fsi.2010.12.023. 
[81] Montagnani C, Kappler C, Reichhart JM, Escoubas JM. Cg-Rel, the first Rel/NF-kappaB homolog characterized in a mollusk, the Pacific oyster Crassostrea gigas. FEBS Lett 2004;561:75-82. doi:10.1016/S0014-5793(04)00124-3.

[82] Green TJ, Barnes AC. Inhibitor of REL/NF-KappaB is regulated in Sydney rock oysters in response to specific double-stranded RNA and Vibrio alginolyticus, but the major immune anti-oxidants EcSOD and Prx6 are non-inducible. Fish Shellfish Immunol 2009;27:260-5. doi:10.1016/j.fsi.2009.05.005.

[83] Hoffmann JA, Kafatos FC, Janeway CA, Ezekowitz RA. Phylogenetic perspectives in innate immunity. Science 1999;284:1313-8.

[84] Munoz M, Vandenbulcke F, Garnier J, Gueguen Y, Bulet P, Saulnier D, et al. Involvement of penaeidins in defense reactions of the shrimp Litopenaeus stylirostris to a pathogenic vibrio. Cell Mol Life Sci 2004;61:961-72. doi:10.1007/s00018-003-3441-9.

[85] Mitta G, Vandenbulcke F, Roch P. Original involvement of antimicrobial peptides in mussel innate immunity. FEBS Lett 2000;486:185-90.

[86] Ganz T, Selsted ME, Szklarek D, Harwig SS, Daher K, Bainton DF, et al. Defensins. Natural peptide antibiotics of human neutrophils. J Clin Invest 1985;76:1427-35. doi:10.1172/JCI112120.

[87] Mitta G, Vandenbulcke F, Noël T, Romestand B, Beauvillain JC, Salzet M, et al. Differential distribution and defence involvement of antimicrobial peptides in mussel. J Cell Sci 2000;113 ( Pt 1:2759-69.

[88] Bevins CL, Salzman NH. Paneth cells, antimicrobial peptides and maintenance of intestinal homeostasis. Nat Rev Microbiol 2011;9:356-68. doi:10.1038/nrmicro2546. 
[89] Cheng TC, Rodrick GE. Lysosomal and other enzymes in the hemolymph of Crassostrea virginica and Mercenaria mercenaria. Comp Biochem Physiol Part B Comp Biochem 1975;52:443-7. doi:10.1016/0305-0491(75)90159-5.

[90] Bachère E, Hervio D, E M. Luminol-dependent chemiluminescence by hemocytes of two marine bivalves, Ostrea edulis and Crassostrea gigas. J Dis Aquat Org 1991;11:173-80.

[91] Lambert C, Soudant P, Choquet G, Paillard C. Measurement of Crassostrea gigas hemocyte oxidative metabolism by flow cytometry and the inhibiting capacity of pathogenic vibrios. Fish Shellfish Immunol 2003;15:225-40.

[92] Cochennec-Laureau N, Auffret M, Renault T, Langlade A. Changes in circulating and tissueinfiltrating hemocyte parameters of European flat oysters, Ostrea edulis, naturally infected with Bonamia ostreae. J Invertebr Pathol 2003;83:23-30.

[93] Labreuche Y, Soudant P, Gonçalves M, Lambert C, Nicolas J-L. Effects of extracellular products from the pathogenic Vibrio aestuarianus strain $01 / 32$ on lethality and cellular immune responses of the oyster Crassostrea gigas. Dev Comp Immunol 2006;30:367-79. doi:10.1016/j.dci.2005.05.003.

[94] Fleury E, Huvet A, Lelong C, de Lorgeril J, Boulo V, Gueguen Y, et al. Generation and analysis of a 29,745 unique Expressed Sequence Tags from the Pacific oyster (Crassostrea gigas) assembled into a publicly accessible database: the GigasDatabase. BMC Genomics 2009;10:341. doi:10.1186/1471-2164-10-341.

[95] Hancock RE, Scott MG. The role of antimicrobial peptides in animal defenses. Proc Natl Acad Sci U S A 2000;97:8856-61. 
[96] Brinkmann V, Reichard U, Goosmann C, Fauler B, Uhlemann Y, Weiss DS, et al. Neutrophil extracellular traps kill bacteria. Science 2004;303:1532-5. doi:10.1126/science.1092385.

[97] Papayannopoulos V, Zychlinsky A. NETs: a new strategy for using old weapons. Trends Immunol 2009;30:513-21. doi:10.1016/j.it.2009.07.011.

[98] Jenne CN, Wong CHY, Zemp FJ, McDonald B, Rahman MM, Forsyth PA, et al. Neutrophils recruited to sites of infection protect from virus challenge by releasing neutrophil extracellular traps. Cell Host Microbe 2013;13:169-80. doi:10.1016/j.chom.2013.01.005.

[99] Guimarães-Costa AB, Nascimento MTC, Wardini AB, Pinto-da-Silva LH, Saraiva EM. ETosis: A Microbicidal Mechanism beyond Cell Death. J Parasitol Res 2012;2012:929743. doi:10.1155/2012/929743.

[100] Wang Y, Li M, Stadler S, Correll S, Li P, Wang D, et al. Histone hypercitrullination mediates chromatin decondensation and neutrophil extracellular trap formation. J Cell Biol 2009;184:205-13. doi:10.1083/jcb.200806072.

[101] Altincicek B, Stötzel S, Wygrecka M, Preissner KT, Vilcinskas A. Host-derived extracellular nucleic acids enhance innate immune responses, induce coagulation, and prolong survival upon infection in insects. J Immunol 2008;181:2705-12.

[102] Donaghy L, Kraffe E, Le Goïc N, Lambert C, Volety AK, Soudant P. Reactive oxygen species in unstimulated hemocytes of the pacific oyster Crassostrea gigas: a mitochondrial involvement. PLoS One 2012;7:e46594. doi:10.1371/journal.pone.0046594.

[103] Hilchie AL, Wuerth K, Hancock REW. Immune modulation by multifaceted cationic host defense (antimicrobial) peptides. Nat Chem Biol 2013;9:761-8. doi:10.1038/nchembio.1393. 
[104] Balseiro P, Falcó A, Romero A, Dios S, Martínez-López A, Figueras A, et al. Mytilus galloprovincialis myticin $\mathrm{C}$ : a chemotactic molecule with antiviral activity and immunoregulatory properties. PLoS One 2011;6:e23140. doi:10.1371/journal.pone.0023140.

[105] Mitta G, Hubert F, Noël T, Roch P. Myticin, a novel cysteine-rich antimicrobial peptide isolated from haemocytes and plasma of the mussel Mytilus galloprovincialis. Eur J Biochem 1999;265:71-8.

[106] Schneider T, Kruse T, Wimmer R, Wiedemann I, Sass V, Pag U, et al. Plectasin, a fungal defensin, targets the bacterial cell wall precursor Lipid II. Science 2010;328:1168-72. doi:10.1126/science. 1185723 .

[107] Segarra A, Baillon L, Tourbiez D, Benabdelmouna A, Faury N, Bourgougnon N, et al. Ostreid herpesvirus type 1 replication and host response in adult Pacific oysters, Crassostrea gigas. Vet Res 2014;45:103. doi:10.1186/s13567-014-0103-x.

[108] Thevissen K, Warnecke DC, François IEJA, Leipelt M, Heinz E, Ott C, et al. Defensins from insects and plants interact with fungal glucosylceramides. J Biol Chem 2004;279:3900-5. doi:10.1074/jbc.M311165200.

[109] Baron OL, van West P, Industri B, Ponchet M, Dubreuil G, Gourbal B, et al. Parental transfer of the antimicrobial protein LBP/BPI protects Biomphalaria glabrata eggs against oomycete infections. PLoS Pathog 2013;9:e1003792. doi:10.1371/journal.ppat.1003792.

[110] Bao B, Peatman E, Li P, He C, Liu Z. Catfish hepcidin gene is expressed in a wide range of tissues and exhibits tissue-specific upregulation after bacterial infection. Dev Comp Immunol 2005;29:939-50. doi:10.1016/j.dci.2005.03.006. 
[111] Thomas CJ, Kapoor M, Sharma S, Bausinger H, Zyilan U, Lipsker D, et al. Evidence of a trimolecular complex involving LPS, LPS binding protein and soluble CD14 as an effector of LPS response. FEBS Lett 2002;531:184-8.

[112] Iovine NM, Elsbach P, Weiss J. An opsonic function of the neutrophil bactericidal/permeability-increasing protein depends on both its $\mathrm{N}$ - and C-terminal domains. Proc Natl Acad Sci U S A 1997;94:10973-8.

[113] Schmitt P, Santini A, Vergnes A, Degremont L, de Lorgeril J. Sequence polymorphism and expression variability of Crassostrea gigas immune related genes discriminate two oyster lines contrasted in term of resistance to summer mortalities. PLoS One 2013;8:e75900. doi:10.1371/journal.pone.0075900.

[114] Thomma BPHJ, Cammue BPA, Thevissen K. Plant defensins. Planta 2002;216:193-202. doi:10.1007/s00425-002-0902-6.

[115] Rothan HA, Mohamed Z, Suhaeb AM, Rahman NA, Yusof R. Antiviral cationic peptides as a strategy for innovation in global health therapeutics for dengue virus: high yield production of the biologically active recombinant plectasin peptide. OMICS 2013;17:560-7. doi:10.1089/omi.2013.0056.

[116] Zhu S, Gao B. Evolutionary origin of $\beta$-defensins. Dev Comp Immunol 2013;39:79-84. doi:10.1016/j.dci.2012.02.011.

[117] Du Pasquier L. [Metazoa immune receptors diversification during evolution]. Med Sci (Paris) 2009;25:273-80. doi:10.1051/medsci/2009253273. 
[118] Pujol N, Zugasti O, Wong D, Couillault C, Kurz CL, Schulenburg H, et al. Anti-fungal innate immunity in C. elegans is enhanced by evolutionary diversification of antimicrobial peptides. PLoS Pathog 2008;4:e1000105. doi:10.1371/journal.ppat.1000105.

[119] Lazzaro BPB. Natural selection on the Drosophila antimicrobial immune system. Curr Opin Microbiol 2008;11:284-9. doi:10.1016/j.mib.2008.05.001.Natural.

[120] Patil A, Hughes AL, Zhang G. Rapid evolution and diversification of mammalian alphadefensins as revealed by comparative analysis of rodent and primate genes. Physiol Genomics 2004;20:1-11. doi:10.1152/physiolgenomics.00150.2004.

[121] Jiggins FM, Kim K-W. The evolution of antifungal peptides in Drosophila. Genetics 2005;171:1847-59. doi:10.1534/genetics.105.045435.

[122] Semple CAM, Taylor K, Eastwood H, Barran PE, Dorin JR. Beta-defensin evolution: selection complexity and clues for residues of functional importance. Biochem Soc Trans 2006;34:257-62. doi:10.1042/BST20060257.

[123] Tennessen J a. Molecular evolution of animal antimicrobial peptides: widespread moderate positive selection. J Evol Biol 2005;18:1387-94. doi:10.1111/j.1420-9101.2005.00925.x.

[124] Dawkins R, Krebs JR. Arms races between and within species. Proc R Soc Lond B Biol Sci 1979;205:489-511.

[125] Tanguy A, Bierne N, Saavedra C, Pina B, Bachère E, Kube M, et al. Increasing genomic information in bivalves through new EST collections in four species: development of new genetic markers for environmental studies and genome evolution. Gene 2008;408:27-36. doi:10.1016/j.gene.2007.10.021. 
[126] Taris N, Lang RP, Reno PW, Camara MD. Transcriptome response of the Pacific oyster (Crassostrea gigas) to infection with Vibrio tubiashii using cDNA AFLP differential display. Anim Genet 2009;40:663-77. doi:10.1111/j.1365-2052.2009.01894.x.

[127] Gueguen Y, Cadoret JP, Flament D, Barreau-Roumiguière C, Girardot AL, Garnier J, et al. Immune gene discovery by expressed sequence tags generated from hemocytes of the bacteria-challenged oyster, Crassostrea gigas. Gene 2003;303:139-45.

[128] Rosa RD, de Lorgeril J, Tailliez P, Bruno R, Piquemal D, Bachère E. A hemocyte gene expression signature correlated with predictive capacity of oysters to survive Vibrio infections. BMC Genomics 2012;13:252. doi:10.1186/1471-2164-13-252.

[129] Rosa R, Alonso P, Santini A, Vergnes A, Bachère E. High polymorphism in big defensin gene expression reveals presence-absence gene variability (PAV) in the oyster Crassostrea gigas. Dev Comp Immunol 2015;49:231-8.

[130] Stranger BE, Forrest MS, Dunning M, Ingle CE, Beazley C, Thorne N, et al. Relative impact of nucleotide and copy number variation on gene expression phenotypes. Science 2007;315:848-53. doi:10.1126/science.1136678.

[131] Springer NM, Ying K, Fu Y, Ji T, Yeh C-T, Jia Y, et al. Maize inbreds exhibit high levels of copy number variation (CNV) and presence/absence variation (PAV) in genome content. PLoS Genet 2009;5:e1000734. doi:10.1371/journal.pgen.1000734.

[132] Linzmeier RM, Ganz T. Human defensin gene copy number polymorphisms: comprehensive analysis of independent variation in alpha- and beta-defensin regions at 8p22-p23. Genomics 2005;86:423-30. doi:10.1016/j.ygeno.2005.06.003. 
[133] Ballana E, González JR, Bosch N, Estivill X. Inter-population variability of DEFA3 gene absence: correlation with haplotype structure and population variability. BMC Genomics 2007;8:14. doi:10.1186/1471-2164-8-14.

[134] Campbell CD, Sampas N, Tsalenko A, Sudmant PH, Kidd JM, Malig M, et al. Populationgenetic properties of differentiated human copy-number polymorphisms. Am J Hum Genet 2011;88:317-32. doi:10.1016/j.ajhg.2011.02.004.

[135] Cantsilieris S, White SJ. Correlating multiallelic copy number polymorphisms with disease susceptibility. Hum Mutat 2013;34:1-13. doi:10.1002/humu.22172.

[136] Swanson-Wagner RA, Eichten SR, Kumari S, Tiffin P, Stein JC, Ware D, et al. Pervasive gene content variation and copy number variation in maize and its undomesticated progenitor. Genome Res 2010;20:1689-99. doi:10.1101/gr.109165.110. 


\section{Figure captions}

Figure 1. Bactericidal/permeability increasing protein is expressed at different level by different hemocyte subsets.

A. Cytometry analysis of SSC and FSC of hemolymph whole cells reveals the three main cell populations: blasts, hyalinocytes, and granulocytes. B. Immunofluorescent labelling of $C g$-BPI protein in hemocytes reveals subset of hyalinocytes and granulocytes with low $C g$-BPI content (white arrowhead) and high $C g$-BPI content (yellow arrowhead). C. Cytometry analysis of $C g$-BPI labelling of each hemocyte populations show that about $40 \%$ of all hemocytes express the BPI that correspong to $40 \%$ of the hyalinocytes and $65 \%$ of the granulocytes. Interestingly among the granulocytes, $30 \%$ of them express $C g$-BPI at a higher level (BPI-High) than the other granulocytes thus defining two granulocyte distinct subsets for the level of $C g$-BPI expression.

Figure 2. Schematic representation of functions of oyster hemocytes. Phagocytosis: After recognition, foreign microorganisms are phagocytosed and can be further destroyed by (i) the production of reactive species of oxygen (ROS) through the NADPH oxidase complex and/or (ii) defense molecules (antimicrobials, hydrolytic enzymes and other effectors) stored in granules that fuse with phagosome; Extracellular trapping: After an exposition to microbial agents or tissue damage, hemocytes release extracellular DNA traps (ETs) associated to histones and granular antimicrobial peptides/proteins, which can entrap microorganisms. Induction of immune genes: Hemocytes can be activated by various mechanisms including tissue damage, stress and microbial recognition by both soluble and cellular pattern recognition proteins/receptors (PRPs) leading to the induction of expression of some immune genes; Secretion of effectors. Immune effectors can be stored in hemocyte cytoplasmic granules or vesicules and released into the plasma, the extracellular spaces or oyster body cavities either continuously or following a microbial challenge or tissue damage.

Figure 3. Phylogenetic tree of animal defensins. Human $\alpha$-defensin 1 (DEFA1) [PDB: 3LO4], chicken $\beta$-defensin (AvB2) [PDB: 2LG5], oyster mantle defensin ( $C g$-Defm) [PDB: 2B58] and horseshoe crab big defensin [PBD: 2RNG]. 
Table 1. Antimicrobial peptides and proteins from the oysters $C$. gigas $(C g)$ and $C$. virginica $(C v)$.

AMP family

Name

Localization

Expression

3D Structure

Antimicrobial activity

References

(microbial

challenge)

\section{Cationic antimicrobial peptides}

Defensins

Cg-Defm

mantle

Cg-Defh1/-2

hemocytes

AOD $(C v)$

gills

hemocytes

Cg-lgPrp

Cg-stPrp

Big defensins

Cg-BigDef1, -2

hemocytes

Cg-BigDef3

hemocytes

Molluscidin

Cg-Molluscidin

mantle

gills constitutive

constitutive

ND

repressed

induced

constitutive

constitutive
ND

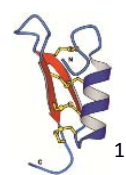

ND

ND

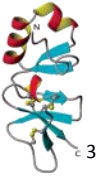

D
Gram (+) / nM range (MIC) Gram (-) / $\mu \mathrm{M}$ range (MIC) Gram (-) / $\mu \mathrm{M}$ range (MEC)

Synergistic activities on Gram (+) and Gram (-) $)^{2}$

ND

ND

Gram (+) / $\mu \mathrm{M}$ range (MEC) Gram (-) / $\mu \mathrm{M}$ range (MEC)

Gram (-) / $\mu \mathrm{M}$ range (MIC)

constitutive

epithelia

all tissues

Macrophage expressed

Cg-Mpeg1

gene 1 like protein

Multifunctional proteins displaying antimicrobial activities

Ubiquitin

Cg-Ubiquitin

gills (infiltrating

Induced? hemocytes?)

gills

ND

gills (infiltrating

ND

hemocytes)

$\begin{array}{ll}\mathrm{CV}-\mathrm{H} 2 \mathrm{~B} & \text { gills } \\ \mathrm{Cg}-\mathrm{H} 1 / \mathrm{H} 5 & \text { gills (infiltrating } \\ & \text { hemocytes) }\end{array}$

constitutive

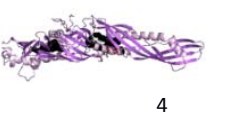

Gram (+) / $\mu \mathrm{M}$ range ${ }^{5}$ Gram (-) / $\mu \mathrm{M}$ range

Seo et al., 2013

Gonzalez et al., 2007

Duperthuy et al., 2010

Seo et al., 2005

Schmitt et al., 2012

Rosa et al., 2012

Gonzalez et al., 2007

He et al., 2011

Gram (+) / $\mu \mathrm{M}$ range (MEC)

Seo et al., 2013

Gram (-) / $\mu \mathrm{M}$ range (MEC)

Gram (+) / $\mu \mathrm{M}$ range (MEC)

Seo et al., 2011

Gram (-) / $\mu \mathrm{M}$ range (MEC)

Poirier et al., 2014

Antimicrobial activities are expressed as Minimal Inhibitory Concentrations (MIC) or Minimal Effective Concentrations (MEC).

ND = not determined.

${ }^{1}$ Three-dimensional structure of $C g$-Defm [PDB: 2B68]

${ }^{2}$ Synergistic activity with $\mathrm{Cg}$-Defs and $\mathrm{Cg}$-BPI

${ }^{3}$ Three-dimensional structure of horseshoe crab (Tachypleus tridentatus) big defensin [PDB: 2RNG] (Kouno et al., 2008).

${ }^{4}$ Predicted structure of bactericidal/permeability-increasing protein (BPI) [PDB: 1BPI] (Beamer et al., 1998).

${ }^{5}$ Partial growth inhibition at $\sim 1 \mu \mathrm{M}$

${ }^{6}$ Predicted structure of $C g$-Ubiquitin according to mouse Tab2-Nzf [PDB ID: 3A9] (Vijay-Kumar et al., 1985) 


\begin{tabular}{|c|c|c|c|c|}
\hline AMPs & Amino acid sequences & No aa & $\begin{array}{l}\text { Mass } \\
(k D a)\end{array}$ & pI \\
\hline \multicolumn{5}{|l|}{ Defensins } \\
\hline Cg-Defh 1 & GFGCPRDQYKCNSHCQSIGCRAGYCDAVTLWLRCTCTDCNGKK & 43 & 4.76 & 8.50 \\
\hline Cg-Defh2 & GFGCPGDQYECNRHCRS IGCRAGYCDAVTLWLRCTCTGCSGKK & 43 & 4.67 & 8.51 \\
\hline$C g-D e f m$ & GFGCPGNQLKCNNHCKS ISCRAGYCDAATLWLRCTCTDCNGKK & 43 & 4.64 & 8.73 \\
\hline \multicolumn{5}{|c|}{ Big defensins } \\
\hline Cg-BigDef1 & $\begin{array}{l}\text { QAQALLPIASYAGLTVSAPVFAALVTVYGAYALYRYNIRRRENSYQRIRSDHDSHSCANNRGWCRPTCFSHE } \\
\text { YTDWFNNDVCGSYRCCRPGRSG }\end{array}$ & 94 & 10.70 & 9.06 \\
\hline Cg-BigDef2 & $\begin{array}{l}\text { QAQALLPIASYAGLAVSPPVFAALVTAYGVYALYRYNIRRENSDHDSHSCANNRGWCRPTCYSYEYTDWFNN } \\
\text { DVCGSYRCCRPGRRG }\end{array}$ & 87 & 9.85 & 8.61 \\
\hline Cg-BigDef3 & $\begin{array}{l}\text { QAQILLPIASYAGLTVTAPVFAALVAAYGIYAVTRYAIRKRRIVMYSDSHSCANNRGWCRESCFSHEYTDWA } \\
\text { NTFGVCGSYFCCRPY }\end{array}$ & 87 & 9.77 & 8.84 \\
\hline \multicolumn{5}{|c|}{ Proline-rich peptides } \\
\hline$C g-\lg \operatorname{Prp}$ & GPIRRPKPRPRPRPE & 15 & 1.80 & 12.18 \\
\hline Cg-stPrp & GPIRRPKPRPRPE & 13 & 1.55 & 12.00 \\
\hline \multicolumn{5}{|c|}{ Bactericidal/permeability increasing proteins } \\
\hline $\mathrm{Cg}-\mathrm{BPI}$ & 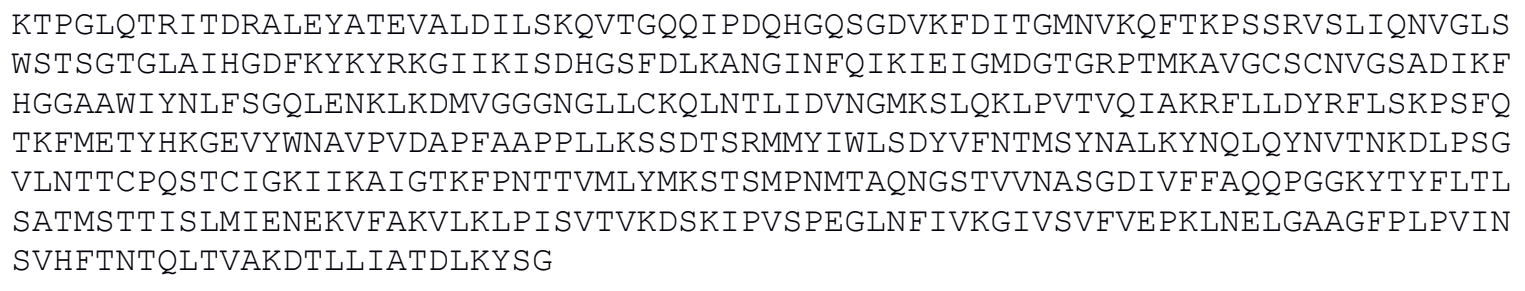 & 458 & 50.14 & 9.37 \\
\hline $\mathrm{Cg}-\mathrm{BPI} 2$ & 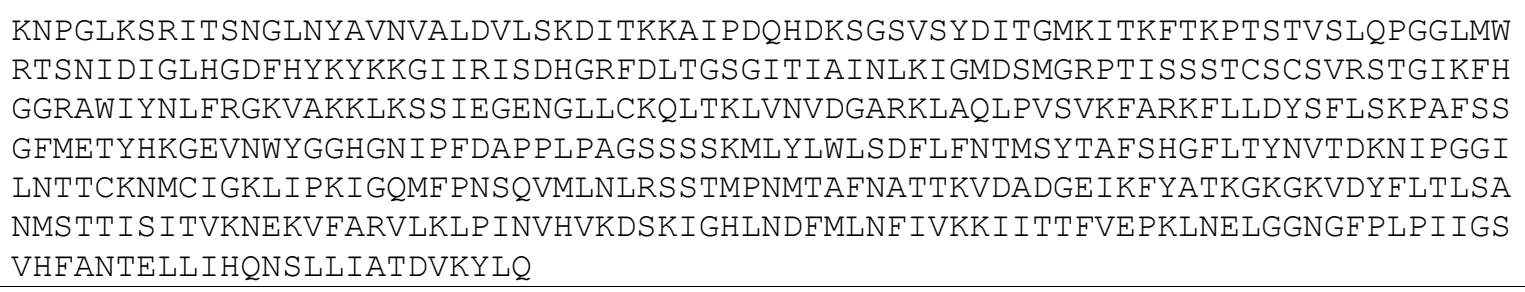 & 457 & 50.3 & 9.74 \\
\hline
\end{tabular}

Table 2. Amino acid sequences of most representative variants of $C$. gigas antimicrobial peptides and proteins. Sequences correspond to the mature peptides. The number of amino acids (aa), molecular weight $(\mathrm{kDa})$ and estimated isoelectric point (pI) of the molecules are indicated on the right of each sequence. 
No nucleotide sequences

\section{Cg-Defs}

mRNA

gDNA

\section{Cg-BigDefs}

mRNA

gDNA

mRNA

gDNA

\section{Cg-BPIs}

mRNA

gDNA

\section{Cg-Lysozymes}

mRNA

gDNA
25

14

80

4

89

23

35

29

nd

3

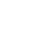

GenBank accession No

FJ669323 to FJ669352;

JF766718 to JF766742;

JF766743 to JF766768,

DQ400101, DQ400102,

AJ565499, AJ582628, AJ582629

FJ669403-FJ669423; AJ582630, AM050547

JF703137 to JF703143, JF703144 to JF703146; JF703147 to JF703153, JN251121, JN251123, JN251124, JN251127, JN251129, JN251130

JF703154 to JF703160; JN251122, JN251125, JN251126, JN251131, JN251132, JF703157, JF703158

FJ669353 to FJ669402; JF766783 to JF766798; JF766775 to JF766782; JF766769 to JF766773

FJ669252 to FJ669286

FJ669296 to FJ669322; AY165040, HM992925

AB179775, AB288344, AB288345, AB307634 JH816436, JH816734, JH819154

nd: non determined

Table 3 : Number of DNA and RNA sequences characterized in Crassotrea gigas among families of antimicrobial peptides and proteins. The accession numbers available in GenBank are indicated. 
A

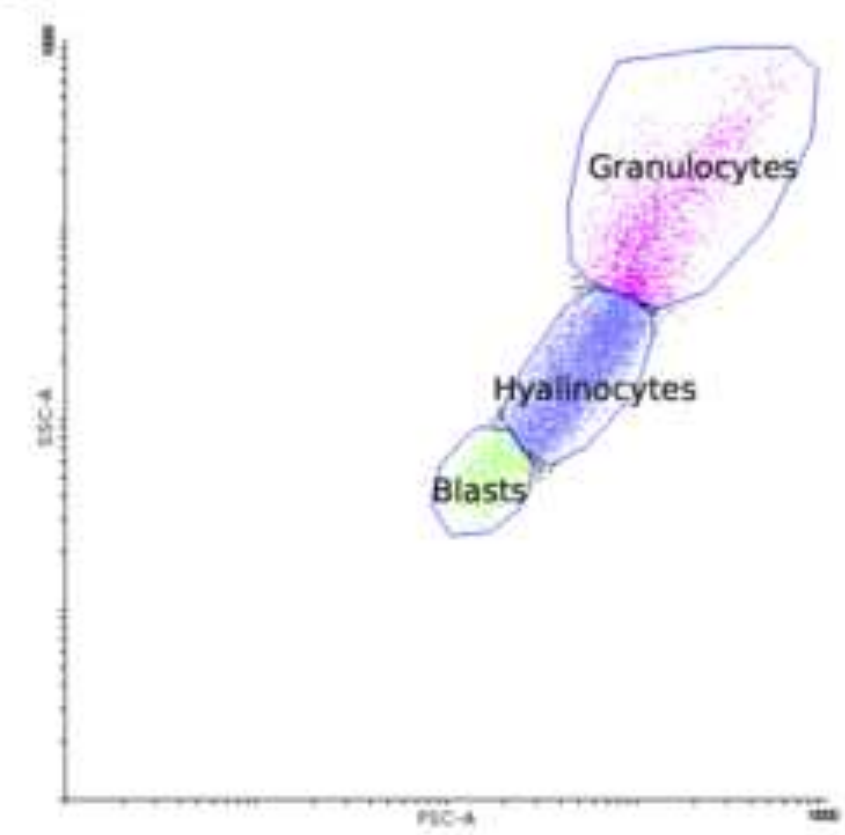

B

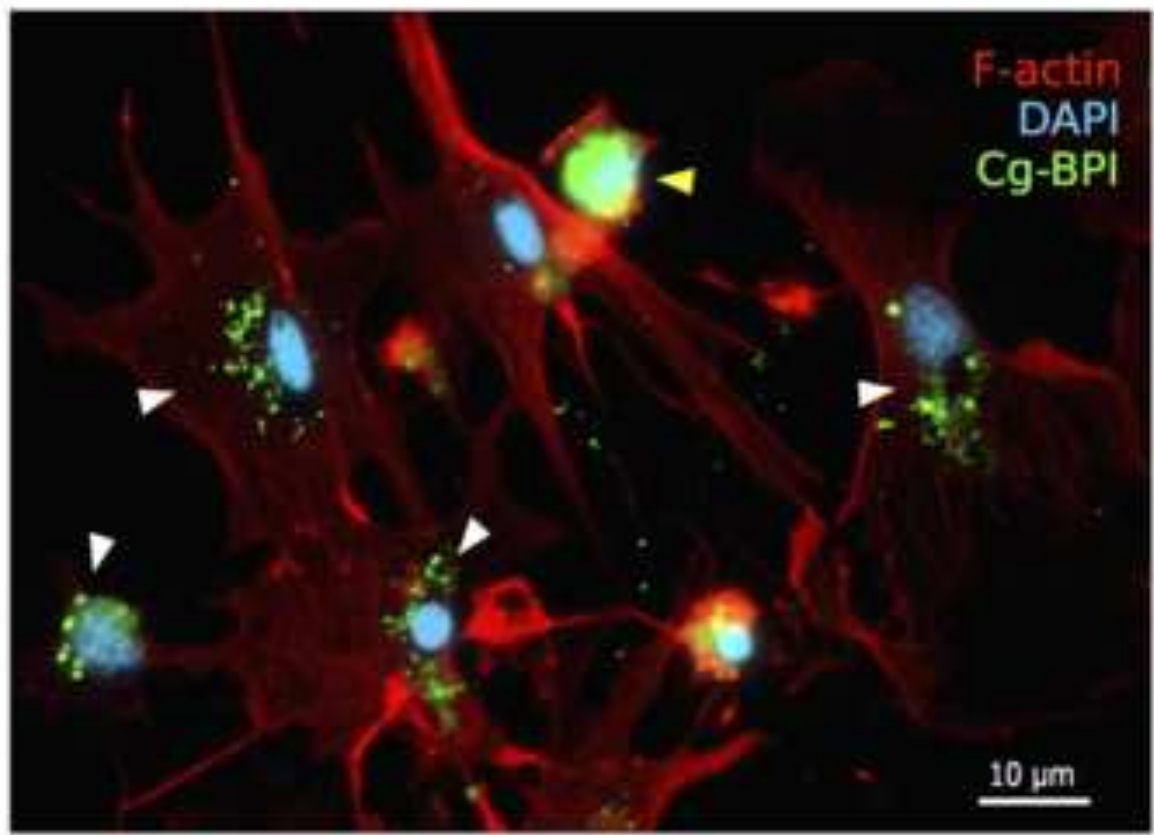

C

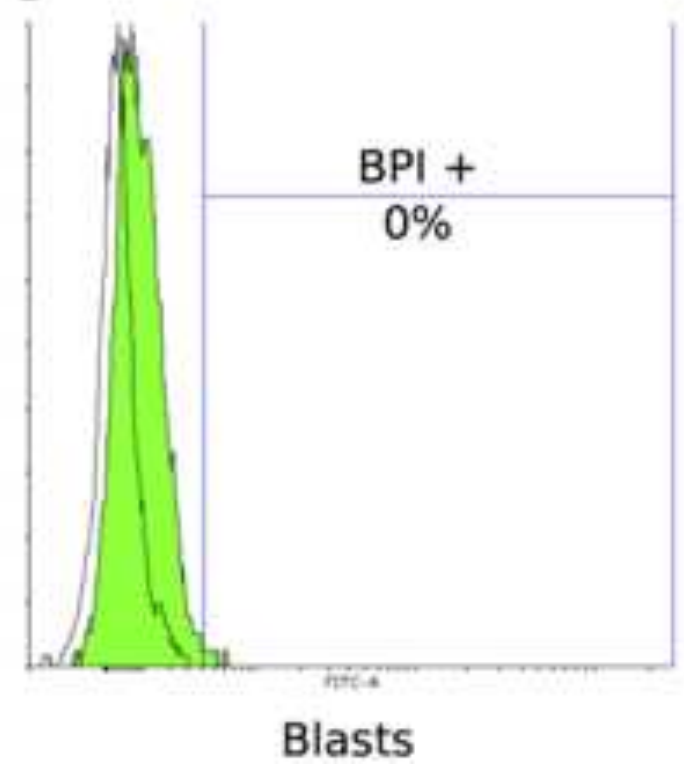

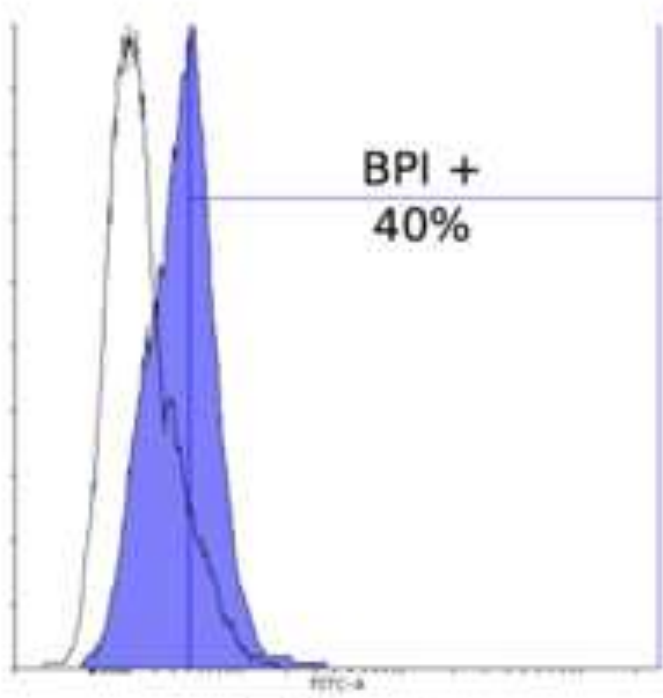

Hyalinocytes

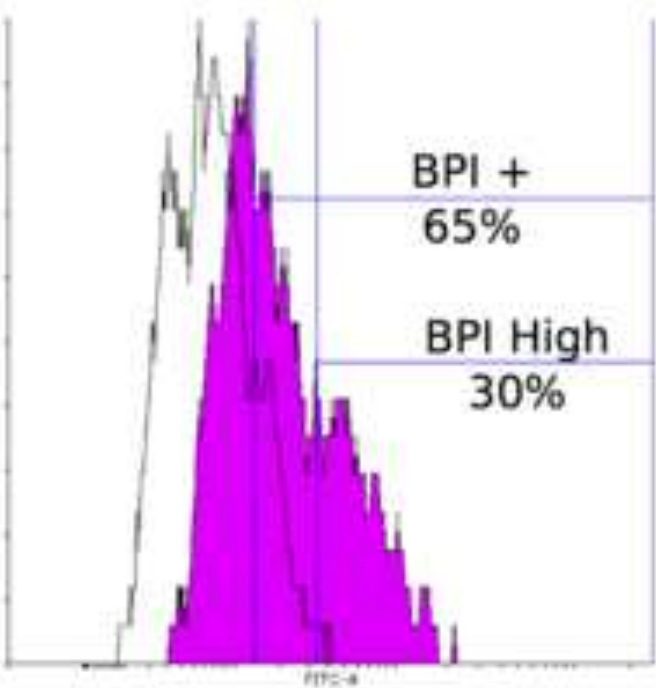

Granulocytes 


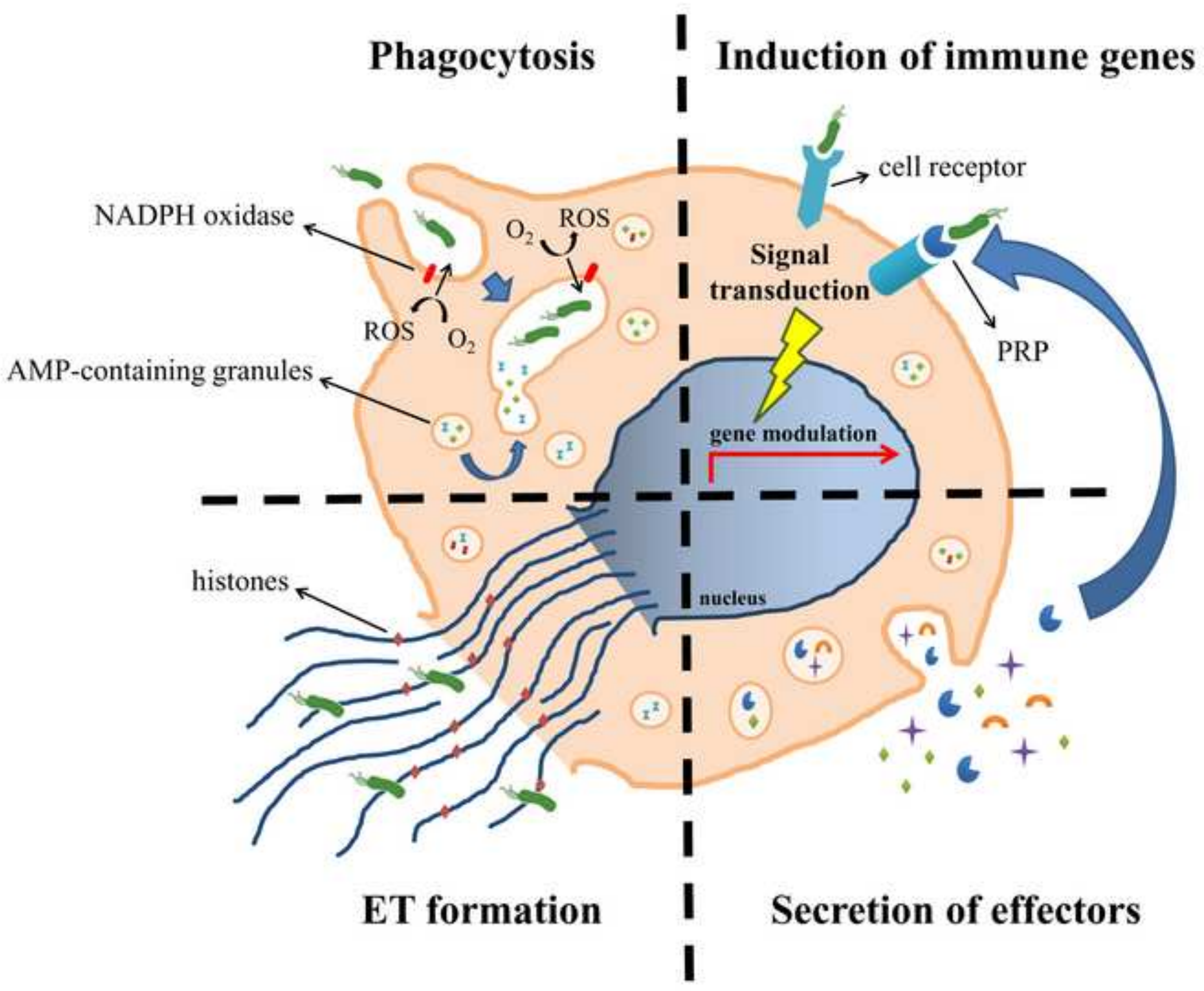




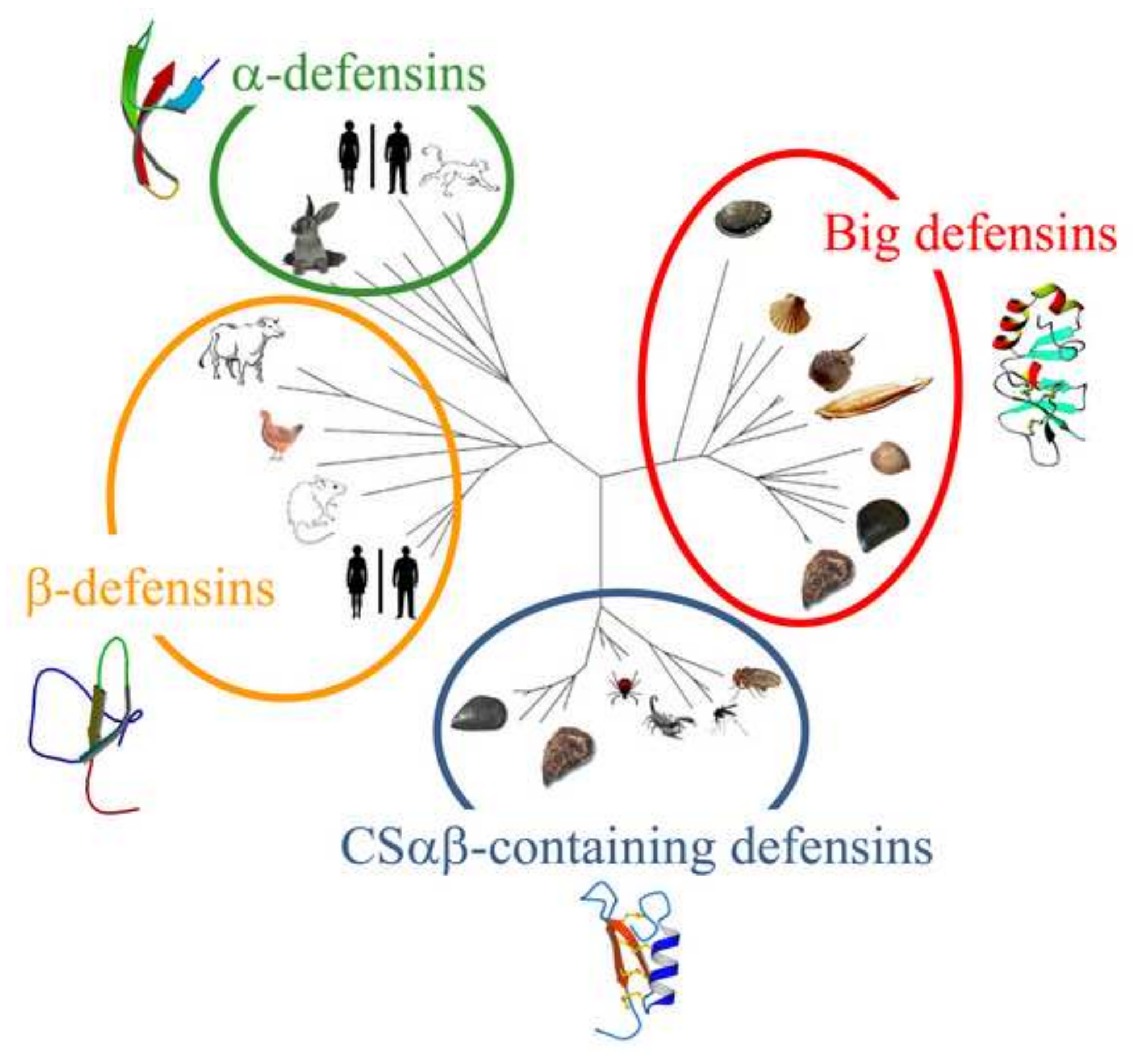

CS $\alpha \beta$-containing defensins

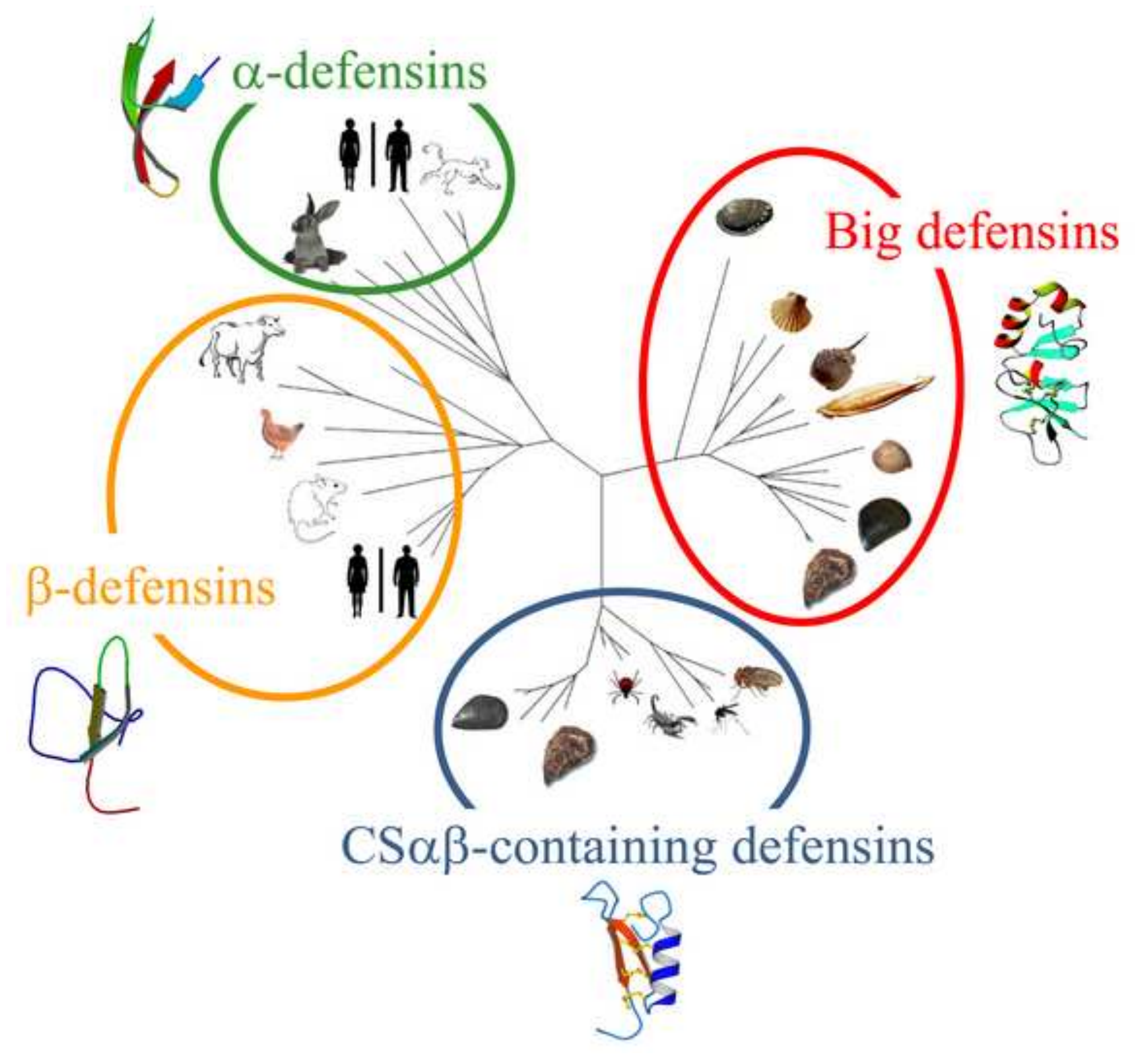

